Supplementary Information for the manuscript

\title{
Photoinduced Conversion of Antimelanoma Agent Dabrafenib to a novel fluorescent BRAF $^{\mathrm{V600E}}$ Inhibitor
}

Boris Pinchuk, Thorsten von Drathen, Viktoria Opel, Christian Peifer

\section{Content}

1. Supplementary Figures

2. Supplementary Tables

3. Methods

4. Supplementary References

1. Supplementary Figures

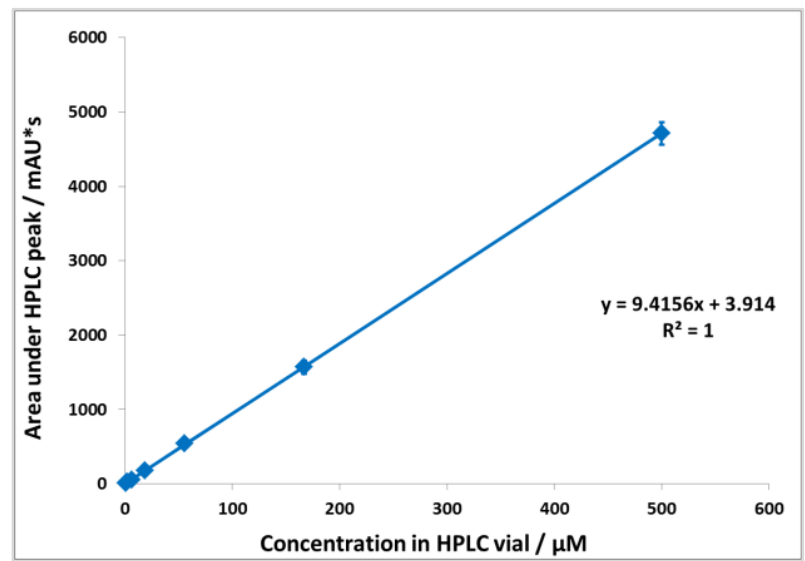

(a)

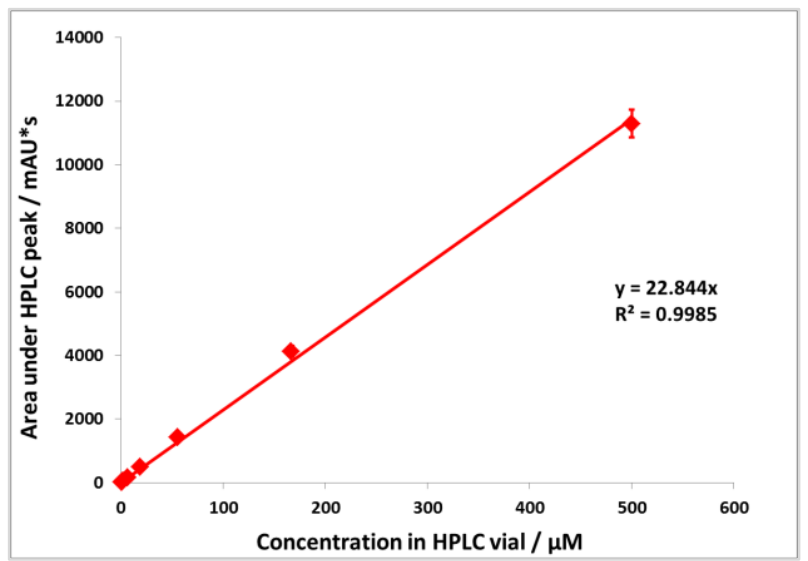

(b)

Figure S1. (a) Calibration curves of dabrafenib (1) and (b) dabrafenib_photo (2) for HPLC analysis. Several solutions with different compound concentrations in DMSO were diluted 1:2 with methanol. The integrated peak area in mAU*s is plotted against the sample end concentration in HPLC vials in $\mu \mathrm{M}$. The stock solutions were prepared in duplicate and each probe was measured twice $(n=4)$. 


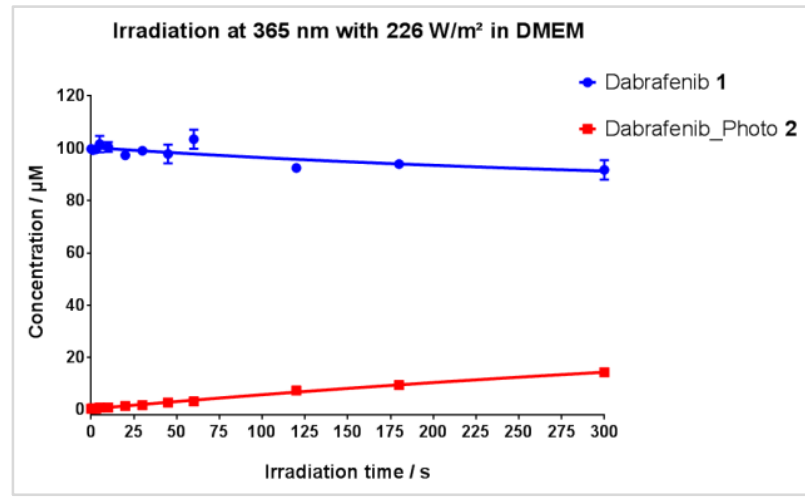

(a)

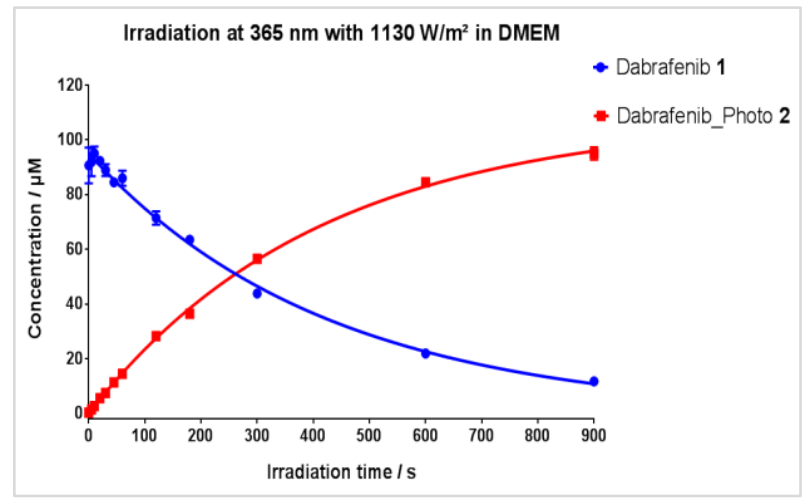

(b)

Figure S2. Irradiation of dabrafenib (1) in cell culture medium DMEM. (a) $200 \mu \mathrm{M}$ solution of 1 in DMEM was irradiated at $365 \mathrm{~nm}$ with $226 \mathrm{~W} / \mathrm{m}^{2}$ for up to $5 \mathrm{~min}(n=2)$. (b) $200 \mu \mathrm{M}$ solution of 1 in DMEM was irradiated at $365 \mathrm{~nm}$ with $1130 \mathrm{~W} / \mathrm{m}^{2}$ for up to $15 \mathrm{~min}$. The irradiated samples were diluted 1:2 with methanol and analyzed by HPLC. The determined areas under the HPLC peaks were converted to appropriate compound's concentrations based on calibration curves (Figure S1) $(n=4)$.

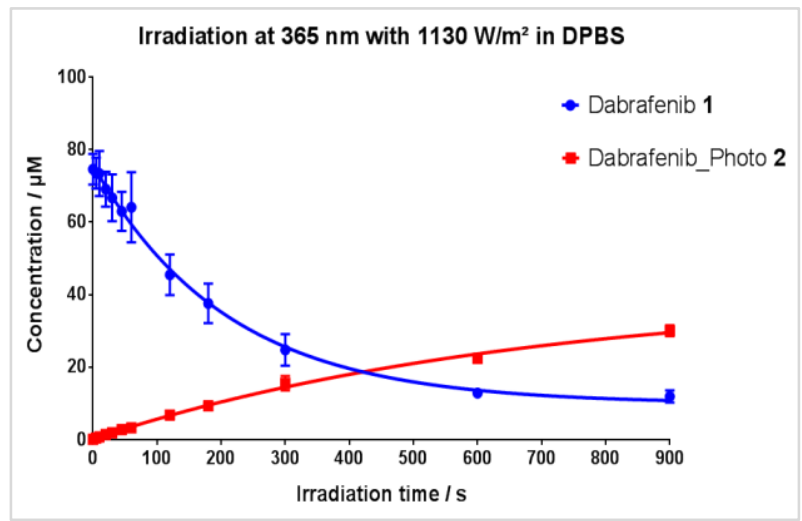

(a)

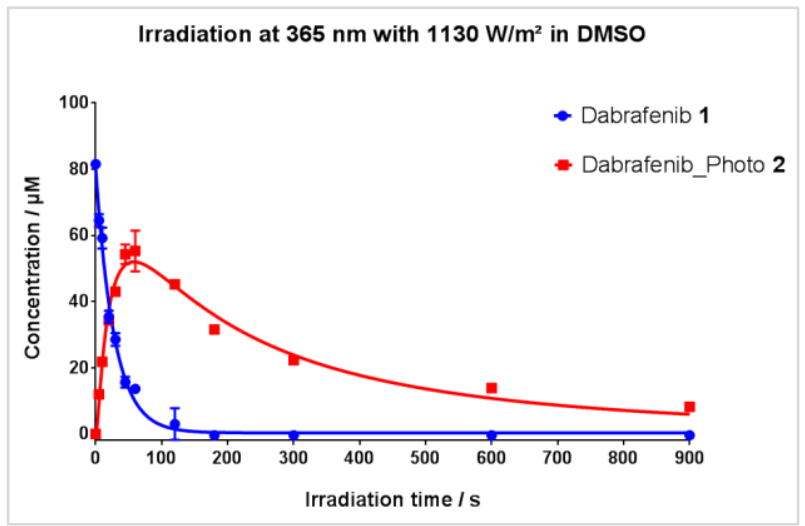

(b)

Figure S3. (a) $200 \mu \mathrm{M}$ solution of 1 in phosphate buffered saline DPBS was irradiated at $365 \mathrm{~nm}$ with $1130 \mathrm{~W} / \mathrm{m}^{2}$ for up to $15 \mathrm{~min}$. (b) $200 \mu \mathrm{M}$ solution of 1 in DMSO was irradiated at $365 \mathrm{~nm}$ with $1130 \mathrm{~W} / \mathrm{m}^{2}$ for up to $15 \mathrm{~min}$. The irradiated samples were diluted 1:2 with methanol and analyzed by HPLC. The determined areas under the HPLC peaks were converted to appropriate compound's concentrations based on calibration curves (Figure S1) $(n=4)$. 


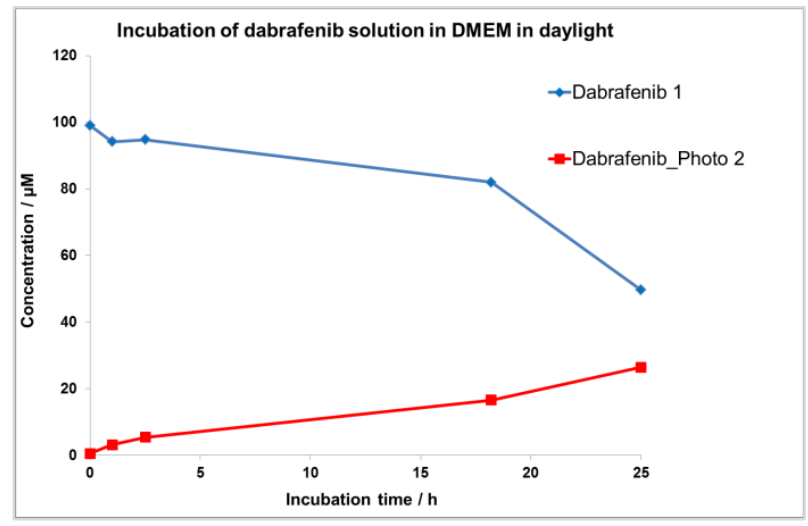

(a)

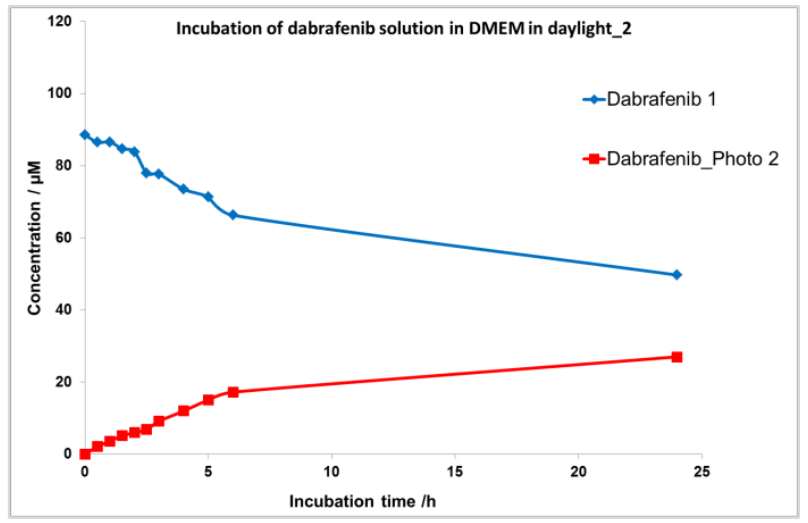

(b)

Figure S4. Stability of $200 \mu \mathrm{M}$ dabrafenib (1) in DMEM under daylight exposure. (a) $200 \mu \mathrm{M}$ solution of 1 in DMEM was incubated for one day at room temperature at a window sill. (b) The experiment was repeated on a sunnier day. The samples were diluted 1:2 with methanol and analyzed by HPLC. The determined areas under the HPLC peaks were converted to appropriate compound's concentrations based on calibration curves (Figure S1).

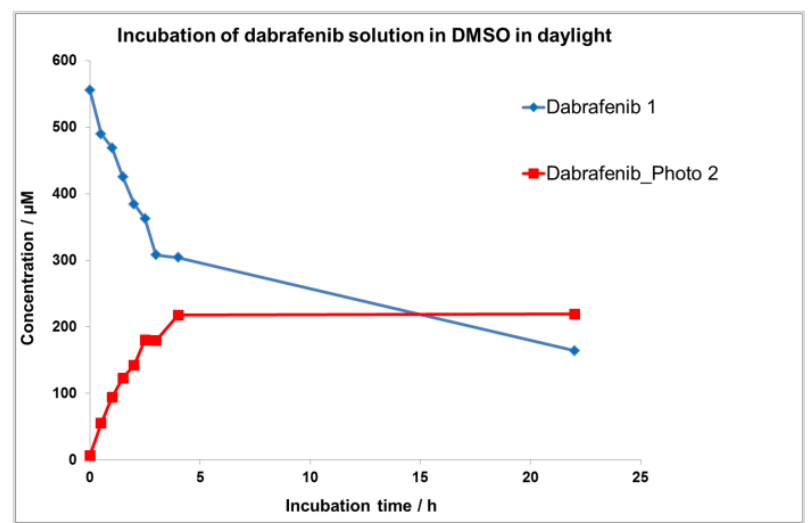

(a)

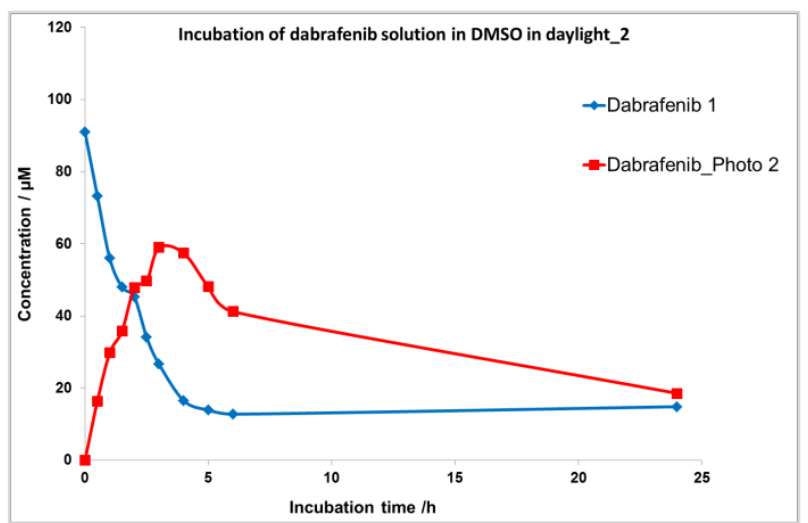

(b)

Figure S5. Stability of dabrafinib in DMSO by daylight. (a) $1100 \mu \mathrm{M}$ solution of $\mathbf{1}$ in DMSO was incubated at room temperature at a window sill. (b) $200 \mu \mathrm{M}$ solution of $\mathbf{1}$ in DMSO was incubated at room temperature at a window sill on a sunnier day than in (a). The samples were diluted 1:2 with methanol and analyzed by HPLC. The determined areas under the HPLC peaks were converted to appropriate compound's concentrations based on calibration curves (Figure S1). 


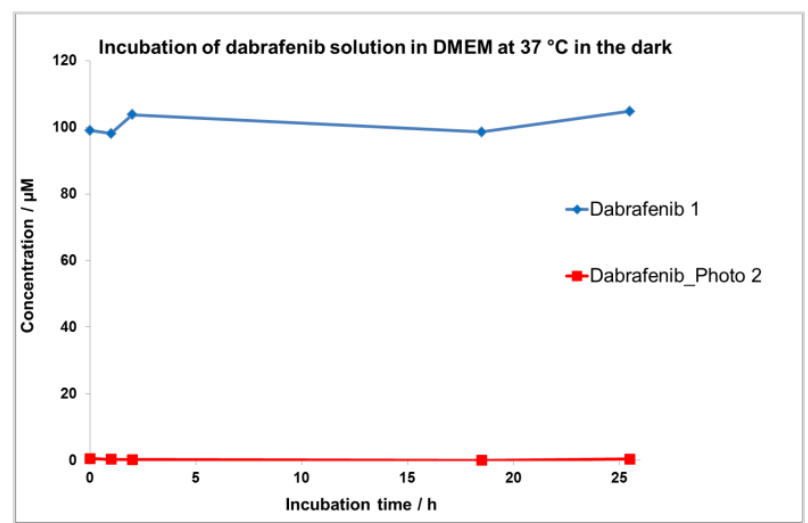

(a)

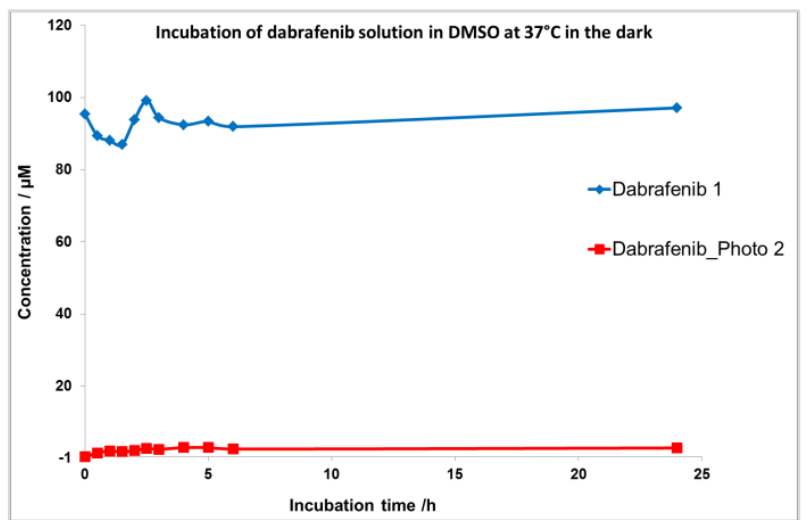

(b)

Figure S6. Stability of $200 \mu \mathrm{M}$ dabrafenib (1) at $37^{\circ} \mathrm{C}$ in the dark. (a) $200 \mu \mathrm{M}$ solution of $\mathbf{1}$ in DMEM was incubated for one day at $37^{\circ} \mathrm{C}$ in dark incubator (b) The experiment was repeated in DMSO. The samples were diluted 1:2 with methanol and analyzed by HPLC. The determined areas under the HPLC peaks were converted to appropriate compound's concentrations based on calibration curves (Figure S1).

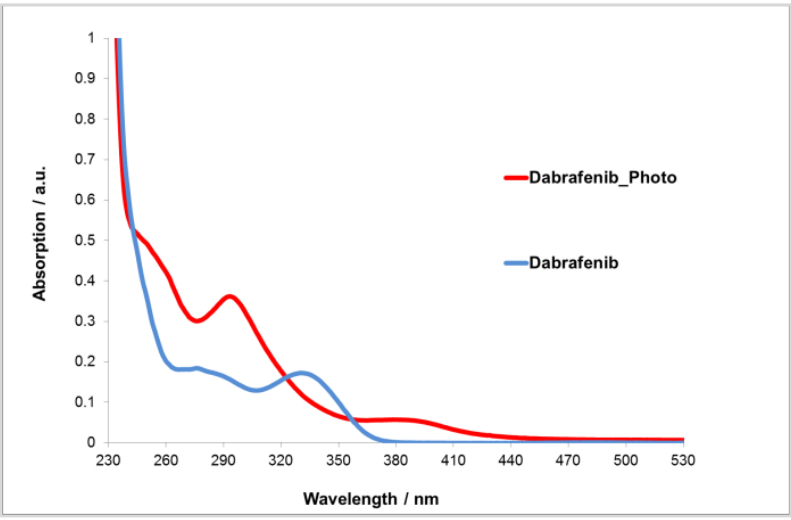

Figure S7. Raw UV/Vis absorption spectra of $20 \mu \mathrm{M}$ compounds in Tris/EDTA (TE) buffer, pH 7.5. 


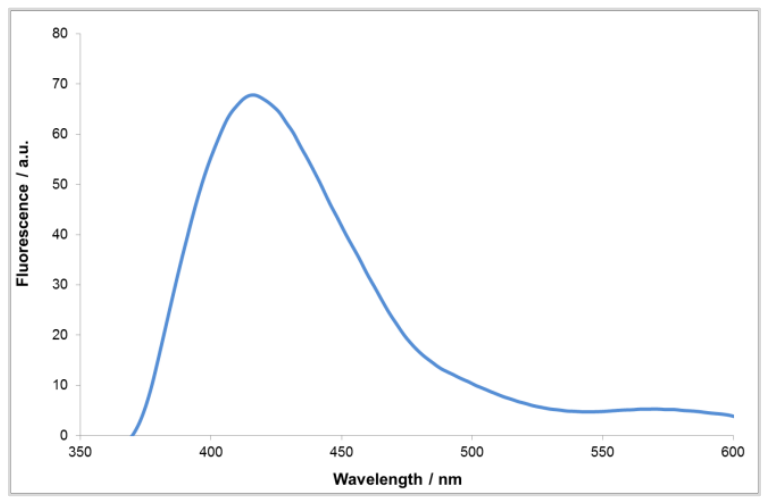

(a)

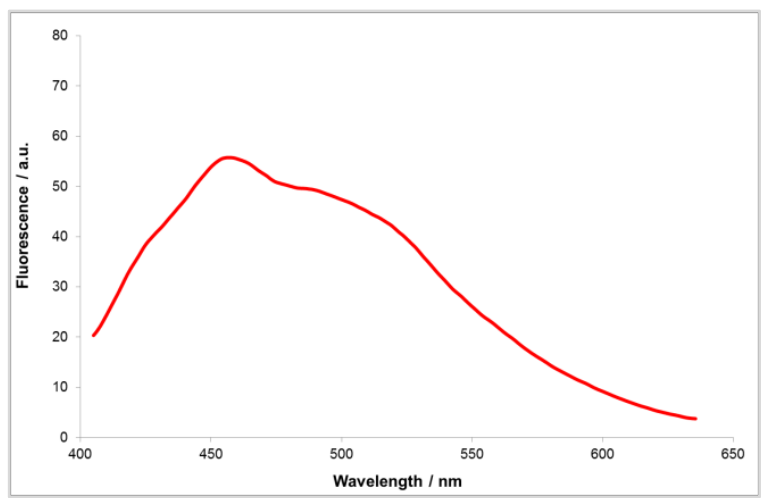

(b)

Figure S8. Raw fluorescence emission spectra of $40 \mu \mathrm{M}$ compounds 1 and 2 in TE buffer, pH 7.5. (a) Fluorescence emission spectrum of dabrafenib (1); Excitation wavelength: $330 \mathrm{~nm}$. (b) Fluorescence emission spectrum of dabrafenib_photo (2); Excitation wavelength: $375 \mathrm{~nm}$.
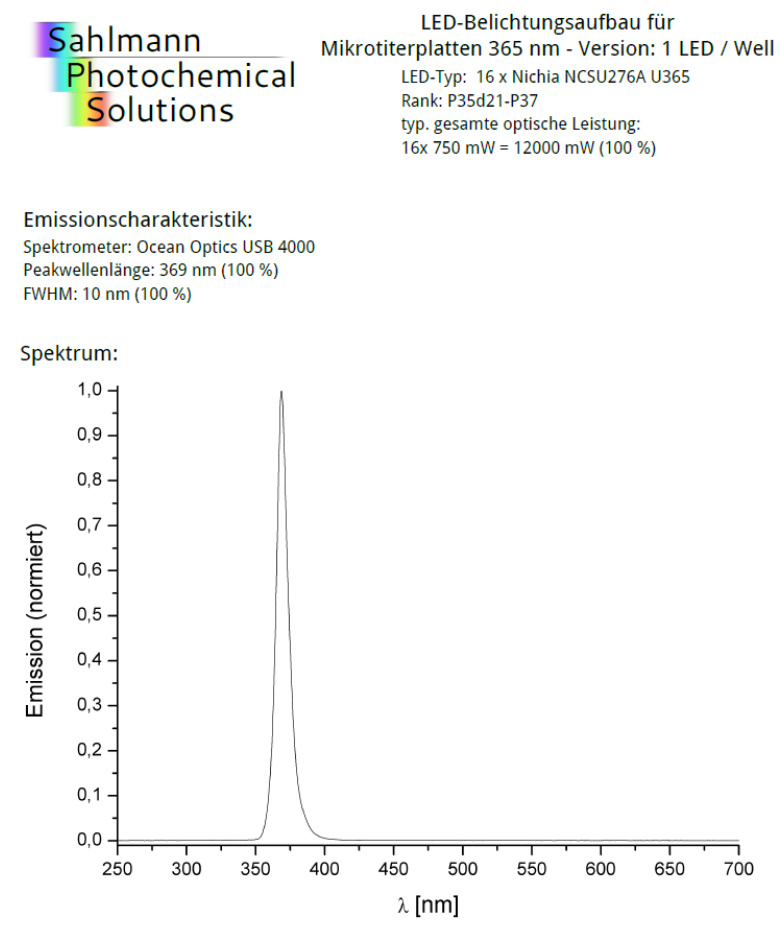

Figure S9. Emission characteristics of the used UV source for irradiation of 96-well microtiter plates. The device consists of 16 equal LEDs with an emission maximum at a wavelength of $369 \mathrm{~nm}$. The added optical power is $12 \mathrm{~W}$ at $100 \%$. The intensity can be adjusted in $1 \%$ steps. Each LED can be exactly positioned above one well of a 96-well plate. Therefore, 16 wells in two columns can be simultaneously irradiated. 


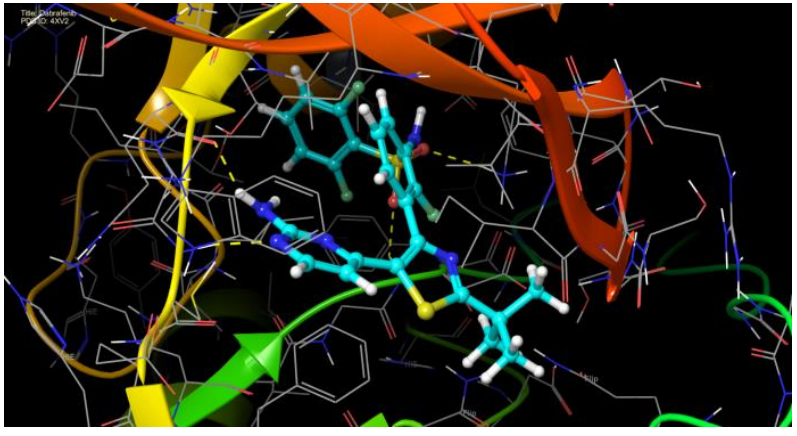

(a)

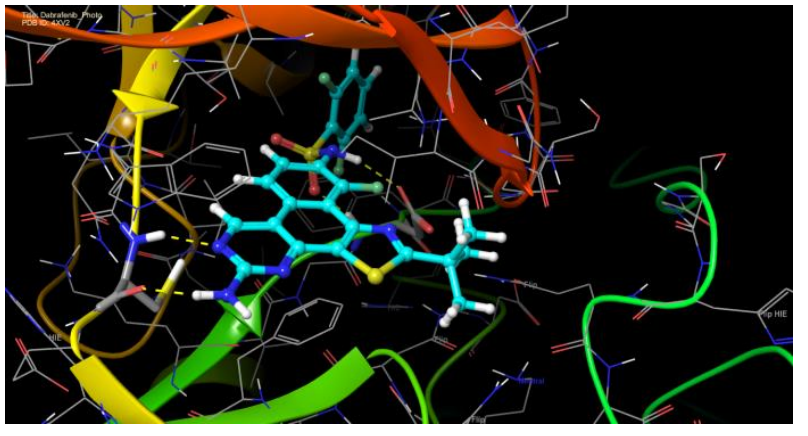

(b)

Figure S10. Modelled binding modes of dabrafenib (1) (a) and dabrafenib_photo (2) (b) in the active site of BRAF ${ }^{\mathrm{V} 600 \mathrm{E}}$ (pdb: $4 \mathrm{XV} 2)$. The carbons of the inhibitors are displayed cyan. The H-Bonds between the ligands and the protein are shown as yellow dashed lines.

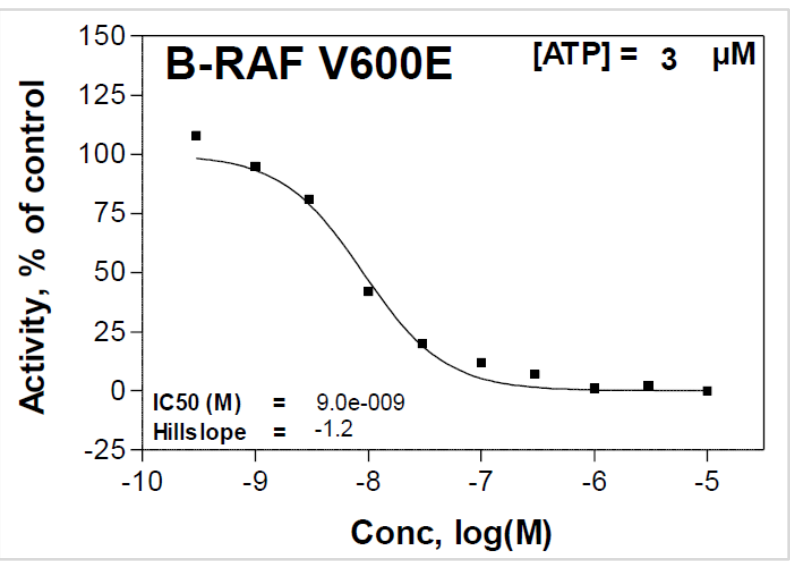

(a)

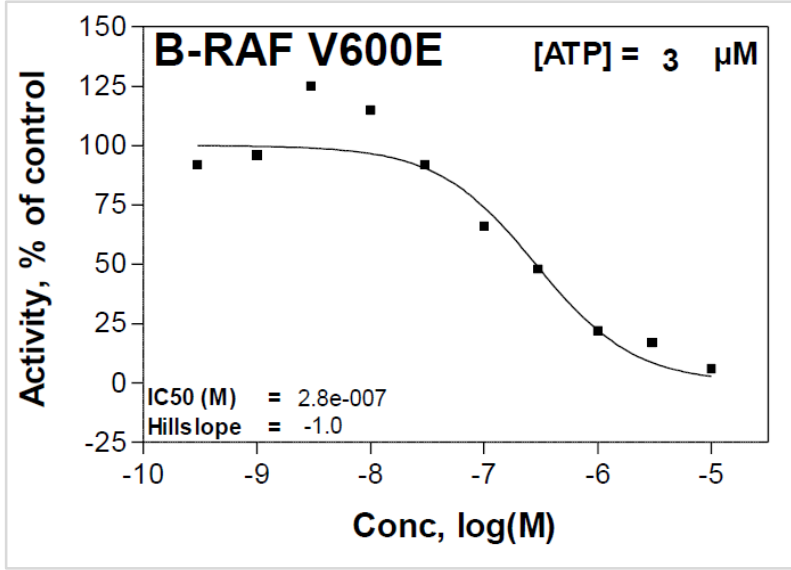

(b)

Figure S11. Determination of $\mathrm{IC}_{50}$ values towards $\mathrm{BRAF}^{\mathrm{V} 600 \mathrm{E}}$. (a) Dose-response curve of dabrafenib (1). (b) Dose-response curve of dabrafenib_photo (2). The kinase assays were performed by ProQinase (Freiburg, Germany). 


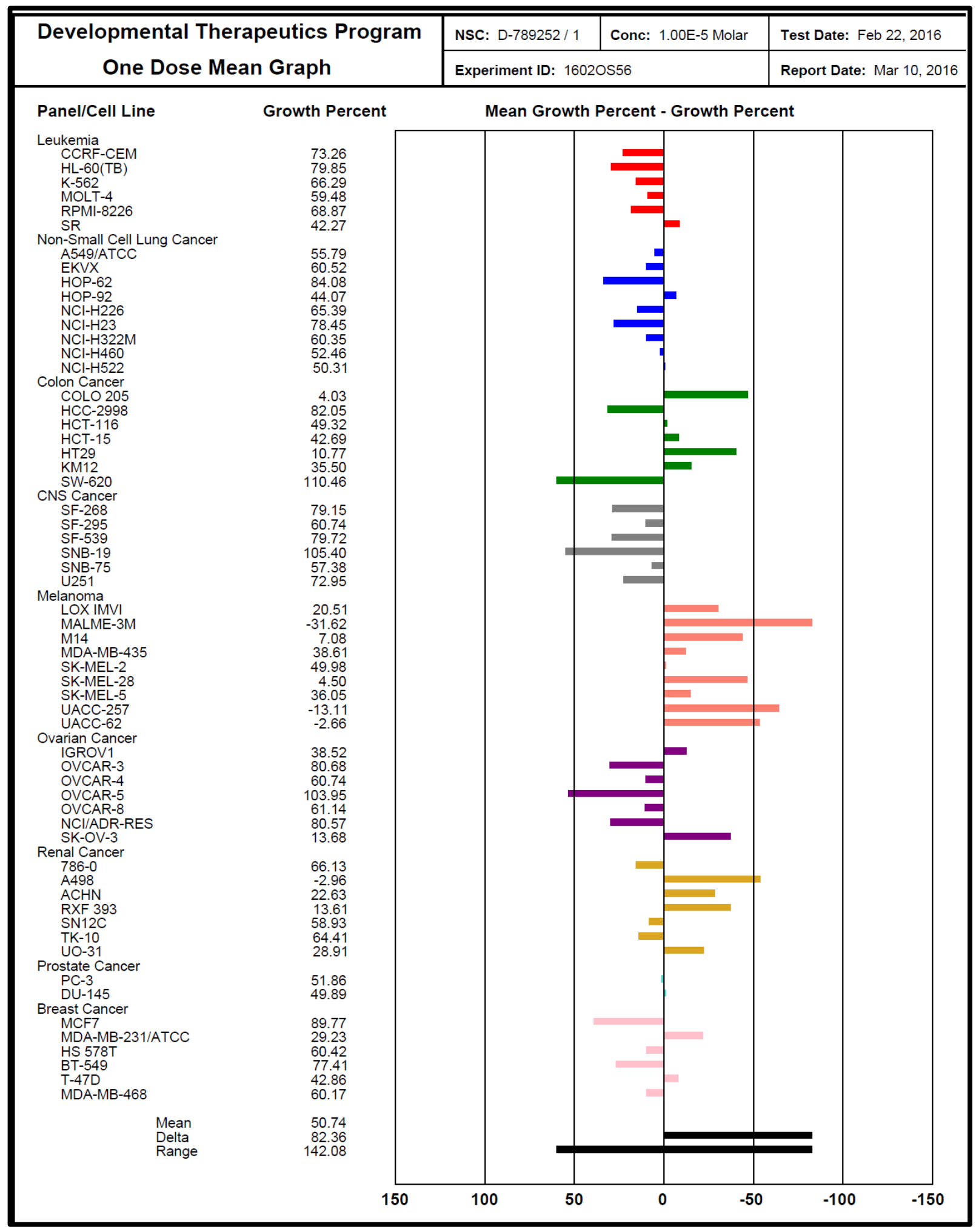

Figure S12. One Dose Mean Graph: Mean cellular growth after incubating of 59 cancer cell lines with $10 \mu \mathrm{M}$ dabrafenib_photo (2). The experiments were performed by NCI (National Cancer Institute, Rockville, MD, USA). 


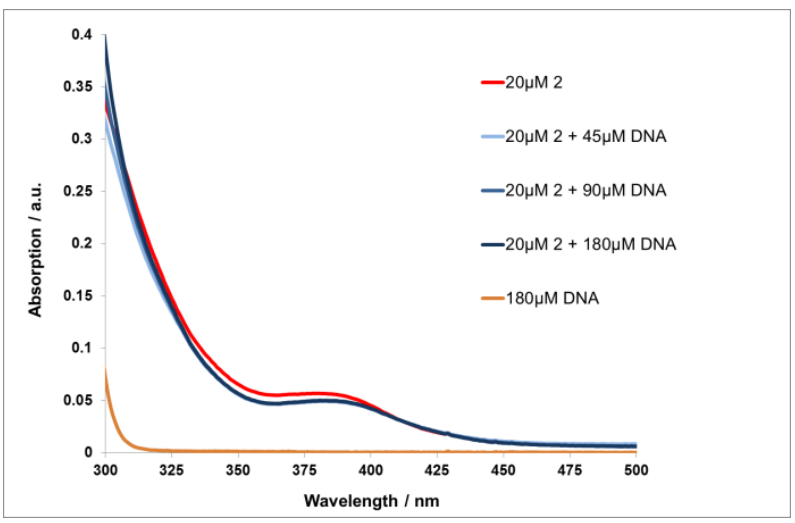

(a)

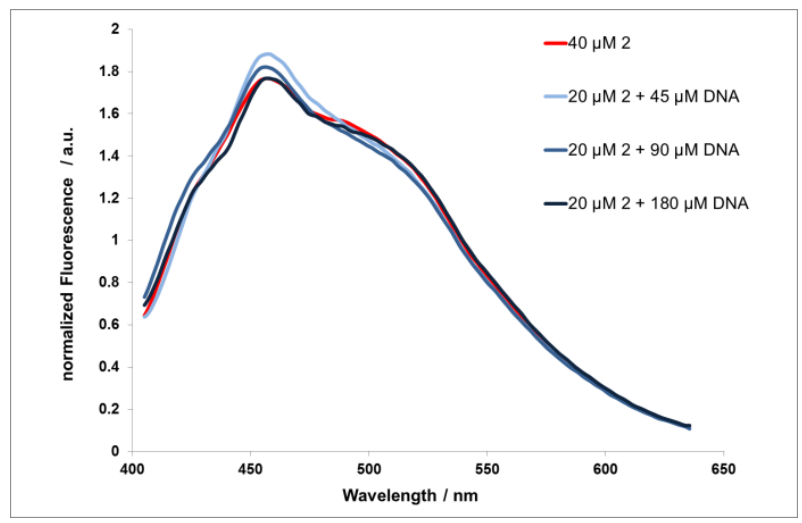

(b)

Figure S13. (a) Raw UV/Vis absorption spectra of $2(20 \mu \mathrm{M})$ incubated with increasing concentration of calf thymus DNA in Tris/EDTA (TE) buffer, pH 7.5 ( $\mathrm{n}=3$ ). (b) Normalized fluorescence emission spectra of compound 2 incubated with increasing concentration of calf thymus DNA in TE buffer, $\mathrm{pH}$ 7.5. Excitation wavelength: $375 \mathrm{~nm}(\mathrm{n}=3)$. Neither the absorption spectra of 2 nor the fluorescence spectra show any significant changes due to DNA addition. Accordingly, there is no evidence for DNA interaction with 2 .

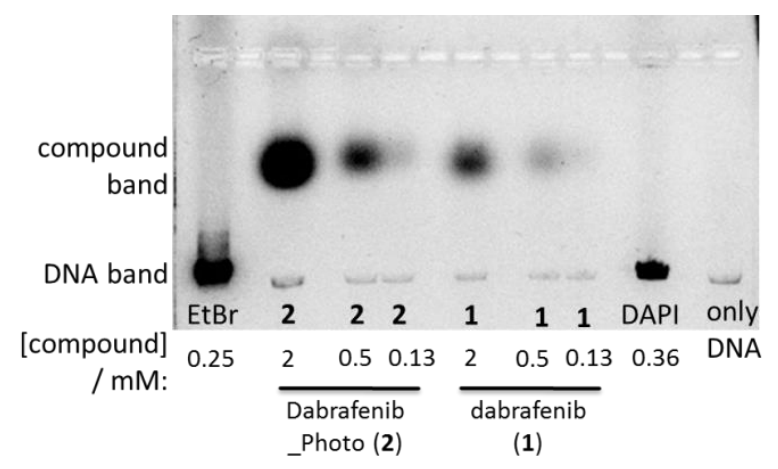

(a)

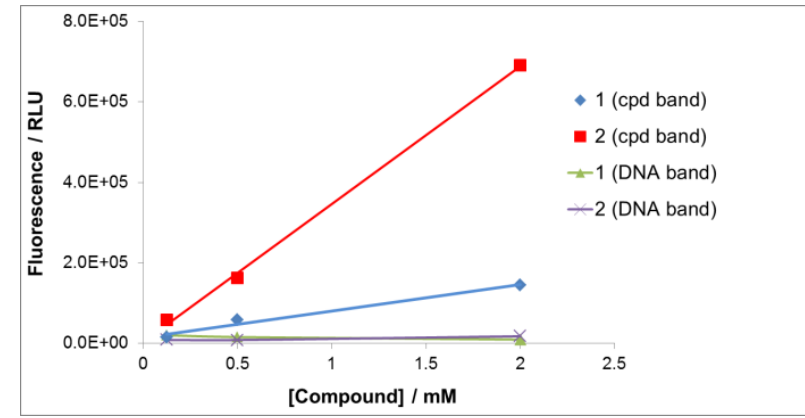

(b)

Figure S14. (a) Agarose gel electrophoresis of a PCR product (DNA) preincubated with different concentrations of 1 and 2. The DNA was stained with two reference dyes: ethidium bromide (EtBr) and DAPI. For the negative control only the PCR product was used (only DNA). Two different bands have been detected: the "compound band" and the "DNA band". It is clearly to see that the compounds 1 and $\mathbf{2}$ show different running behavior than the DNA. (b) The fluorescence intensity of individual spots in the compound (cpd) and DNA bands was quantified for $\mathbf{1}$ and $\mathbf{2}$. The intensities are plotted against the compound concentration. The intensity of the spots in the compound band is linear to the compound's concentration. The intensity of the DNA band is in the range of the negative control. There is no evidence for DNA staining by the compounds. 


\section{Supplementary Tables}

Table S1. Half-live periods for photoinduced decay of $200 \mu \mathrm{M}$ dabrafenib $\mathbf{1}$ in different solvents, when irradiated by UV light at $365 \mathrm{~nm}$ with $1130 \mathrm{~W} / \mathrm{m}^{2}$.

\begin{tabular}{|c|c|c|c|}
\hline Solvent & DMSO & DPBS & DMEM \\
\hline Half-live / s & 19.5 & 145 & 294 \\
\hline
\end{tabular}

Table S2. Kinase profiling of dabrafenib (1) and dabrafenib_photo (2). The inhibitory effect of active compounds was tested on a panel of 321 kinases. The residual activity of kinases was measured after incubation with $1 \mu \mathrm{M}$ of each compound. The data is portrayed as mean percentage residual activity. (ProQinase, Freiburg, Germany).

\begin{tabular}{|c|c|c|c|}
\hline Kinase & $\begin{array}{c}\text { Kinase } \\
\text { Family* }\end{array}$ & Dabrafenib_photo (2) & Dabrafenib (1) \\
\hline ABL1 & TK & 93 & 94 \\
\hline ABL2 & TK & 99 & 77 \\
\hline ACK1 & TK & 75 & 29 \\
\hline ACV-R1 & TKL & 79 & 47 \\
\hline ACV-R1B & TKL & 84 & 22 \\
\hline ACV-R2A & TKL & 74 & 9 \\
\hline ACV-R2B & TKL & 88 & 46 \\
\hline ACV-RL1 & TKL & 87 & 75 \\
\hline AKT1 aa106-480 & $\mathrm{AGC}$ & 88 & 94 \\
\hline AKT2 aa107-481 & AGC & 114 & 91 \\
\hline AKT3 aa106-479 & AGC & 89 & 80 \\
\hline ALK (GST-HIS-tag) & TK & 104 & 105 \\
\hline AMPK-alpha1 aa1-550 & CAMK & 81 & 49 \\
\hline ARK5 & CAMK & 95 & 101 \\
\hline ASK1 & STE & 104 & 98 \\
\hline Aurora-A & OTHER & 103 & 102 \\
\hline Aurora-B & OTHER & 90 & 81 \\
\hline Aurora-C & OTHER & 104 & 92 \\
\hline AXL & TK & 100 & 75 \\
\hline BLK & TK & 52 & 29 \\
\hline BMPR1A & TKL & 96 & 48 \\
\hline BMX & TK & 87 & 75 \\
\hline B-RAF V600E & TKL & 27 & 1 \\
\hline B-RAF & TKL & 27 & 5 \\
\hline BRK & TK & 104 & 26 \\
\hline BRSK1 & CAMK & 102 & 105 \\
\hline BRSK2 & CAMK & 88 & 50 \\
\hline BTK & TK & 75 & 96 \\
\hline BUB1B & OTHER & 89 & 101 \\
\hline CAMK1D & CAMK & 97 & 116 \\
\hline CAMK2A & CAMK & 80 & 81 \\
\hline CAMK2B & CAMK & 83 & 78 \\
\hline CAMK2D & CAMK & 96 & 97 \\
\hline CAMK2G & CAMK & 118 & 102 \\
\hline
\end{tabular}




\begin{tabular}{|c|c|c|c|}
\hline CAMK4 & CAMK & 94 & 91 \\
\hline CAMKK1 & OTHER & 88 & 95 \\
\hline CAMKK2 & OTHER & 107 & 113 \\
\hline CDC42BPA & AGC & 82 & 88 \\
\hline CDC42BPB & AGC & 100 & 98 \\
\hline CDC7/ASK & OTHER & 95 & 92 \\
\hline CDK1/CycA2 & CMGC & 100 & 84 \\
\hline CDK1/CycB1 & CMGC & 89 & 89 \\
\hline CDK1/CycE1 & CMGC & 83 & 57 \\
\hline CDK19/СycC & CMGC & 98 & 94 \\
\hline CDK2/CycA2 & CMGC & 70 & 72 \\
\hline CDK2/CycE1 & CMGC & 93 & 90 \\
\hline CDK3/CycC & CMGC & 97 & 86 \\
\hline CDK3/CycE1 & CMGC & 98 & 103 \\
\hline CDK4/CycD1 & CMGC & 88 & 97 \\
\hline CDK4/CycD3 & CMGC & 100 & 119 \\
\hline CDK5/p25NCK & CMGC & 101 & 98 \\
\hline CDK5/p35NCK & CMGC & 77 & 82 \\
\hline CDK6/CycD1 & CMGC & 113 & 104 \\
\hline CDK6/CycD3 & & 97 & 74 \\
\hline CDK7/CycH/MAT1 & CMGC & 123 & 109 \\
\hline CDK8/CycC & CMGC & 100 & 109 \\
\hline CDK9/CycK & CMGC & 93 & 98 \\
\hline CDK9/CycT1 & CMGC & 102 & 106 \\
\hline CHK1 & CAMK & 94 & 100 \\
\hline CHK2 & CAMK & 72 & 103 \\
\hline CK1-alpha1 & CK1 & 86 & 94 \\
\hline CK1-delta & CK1 & 79 & 81 \\
\hline CK1-epsilon & CK1 & 84 & 89 \\
\hline CK1-gamma1 & CK1 & 63 & 96 \\
\hline CK1-gamma2 & CK1 & 104 & 101 \\
\hline CK1-gamma3 & CK1 & 86 & 91 \\
\hline CK2-alpha1 & OTHER & 88 & 85 \\
\hline CK2-alpha2 & OTHER & 94 & 84 \\
\hline CLK1 & CMGC & 91 & 89 \\
\hline CLK2 & CMGC & 90 & 98 \\
\hline CLK3 & CMGC & 82 & 74 \\
\hline CLK4 & CMGC & 81 & 74 \\
\hline COT & STE & 93 & 85 \\
\hline CSF1-R & TK & 109 & 109 \\
\hline CSK & TK & 87 & 34 \\
\hline DAPK1 & CAMK & 79 & 75 \\
\hline DAPK2 & CAMK & 81 & 92 \\
\hline DAPK3 & CAMK & 58 & 54 \\
\hline DCAMKL2 & CAMK & 90 & 77 \\
\hline DDR2 & TK & 69 & 14 \\
\hline DMPK & $\mathrm{AGC}$ & 95 & 103 \\
\hline DNA-PK & ATYP & 94 & 92 \\
\hline DYRK1A & CMGC & 88 & 90 \\
\hline
\end{tabular}




\begin{tabular}{|c|c|c|c|}
\hline DYRK1B & CMGC & 106 & 98 \\
\hline DYRK2 & CMGC & 94 & 98 \\
\hline DYRK3 & CMGC & 83 & 91 \\
\hline DYRK4 & CMGC & 92 & 38 \\
\hline EEF2K & ATYPICAL & 88 & 93 \\
\hline EGF-R & TK & 104 & 119 \\
\hline EIF2AK2 & OTHER & 93 & 95 \\
\hline EIF2AK3 & OTHER & 47 & 4 \\
\hline EPHA1 & TK & 94 & 81 \\
\hline EPHA2 & TK & 109 & 133 \\
\hline EPHA3 & TK & 92 & 91 \\
\hline EPHA4 & TK & 99 & 97 \\
\hline EPHA5 & TK & 109 & 116 \\
\hline EPHA6 & TK & 99 & 72 \\
\hline EPHA7 & TK & 96 & 102 \\
\hline EPHA8 & TK & 95 & 105 \\
\hline EPHB1 & TK & 76 & 94 \\
\hline EPHB2 & TK & 91 & 94 \\
\hline EPHB3 & TK & 93 & 92 \\
\hline EPHB4 & TK & 93 & 97 \\
\hline ERBB2 & TK & 109 & 96 \\
\hline ERBB4 & TK & 80 & 91 \\
\hline ERK1 & CMGC & 84 & 92 \\
\hline ERK2 & CMGC & 99 & 88 \\
\hline ERK5 & CMGC & 80 & 74 \\
\hline ERK7 & CMGC & 81 & 80 \\
\hline FAK aa2-1052 & TK & 99 & 89 \\
\hline FER & TK & 111 & 94 \\
\hline FES & TK & 93 & 88 \\
\hline FGF-R1 & TK & 90 & 89 \\
\hline FGF-R2 & TK & 91 & 92 \\
\hline FGF-R3 & TK & 91 & 118 \\
\hline FGF-R4 & TK & 104 & 93 \\
\hline FGR & TK & 91 & 60 \\
\hline FLT3 & TK & 104 & 117 \\
\hline FRK & TK & 103 & 111 \\
\hline FYN & TK & 97 & 36 \\
\hline GRK2 & AGC & 90 & 95 \\
\hline GRK3 & AGC & 96 & 86 \\
\hline GRK4 & AGC & 70 & 59 \\
\hline GRK5 & AGC & 84 & 85 \\
\hline GRK6 & AGC & 76 & 79 \\
\hline GRK7 & AGC & 81 & 76 \\
\hline GSG2 & OTHER & 118 & 147 \\
\hline GSK3-alpha & CMGC & 88 & 97 \\
\hline GSK3-beta & CMGC & 91 & 97 \\
\hline HCK & TK & 82 & 91 \\
\hline HIPK1 & CMGC & 81 & 87 \\
\hline HIPK2 & CMGC & 80 & 80 \\
\hline
\end{tabular}




\begin{tabular}{|c|c|c|c|}
\hline HIPK3 & CMGC & 96 & 99 \\
\hline HIPK4 & CMGC & 82 & 37 \\
\hline HRI & OTHER & 69 & 16 \\
\hline IGF1-R & TK & 100 & 81 \\
\hline IKK-alpha & OTHER & 88 & 97 \\
\hline IKK-beta & OTHER & 79 & 94 \\
\hline IKK-epsilon & OTHER & 90 & 97 \\
\hline INS-R & TK & 112 & 108 \\
\hline INSR-R & TK & 107 & 103 \\
\hline IRAK1 & TKL & 90 & 84 \\
\hline IRAK4 (untagged) & TKL & 90 & 103 \\
\hline ITK & TK & 94 & 109 \\
\hline JAK1 aa850-1154 & TK & 90 & 84 \\
\hline JAK2 & TK & 85 & 90 \\
\hline JAK3 & TK & 100 & 115 \\
\hline JNK1 & CMGC & 75 & 89 \\
\hline JNK2 & CMGC & 95 & 105 \\
\hline JNK3 & CMGC & 70 & 118 \\
\hline KIT & TK & 95 & 94 \\
\hline LCK & TK & 80 & 38 \\
\hline LIMK1 & TKL & 100 & 98 \\
\hline LIMK2 & TKL & 92 & 87 \\
\hline LRRK2 & TKL & 93 & 102 \\
\hline LTK & TK & 90 & 93 \\
\hline LYN & TK & 87 & 51 \\
\hline MAP3K1 & STE & 90 & 84 \\
\hline MAP3K10 & STE & 102 & 91 \\
\hline MAP3K11 & STE & 22 & 55 \\
\hline MAP3K7/MAP3K7IP1 & STE & 86 & 76 \\
\hline MAP3K9 & STE & 66 & 70 \\
\hline MAP4K2 & STE & 114 & 115 \\
\hline MAP4K4 & STE & 95 & 95 \\
\hline MAP4K5 & STE & 87 & 90 \\
\hline MAPKAPK2 & CAMK & 69 & 69 \\
\hline MAPKAPK3 & CAMK & 93 & 92 \\
\hline MAPKAPK5 & CAMK & 83 & 37 \\
\hline MARK1 & CAMK & 90 & 90 \\
\hline MARK2 & CAMK & 92 & 94 \\
\hline MARK3 & CAMK & 99 & 96 \\
\hline MARK4 & CAMK & 88 & 84 \\
\hline MATK & TK & 101 & 90 \\
\hline MEK1 & STE & 79 & 94 \\
\hline MEK2 & STE & 92 & 91 \\
\hline MEK5 & STE & 80 & 90 \\
\hline MEKK2 & STE & 83 & 57 \\
\hline MEKK3 & STE & 117 & 96 \\
\hline MELK & CAMK & 41 & 27 \\
\hline MERTK & TK & 124 & 115 \\
\hline MET & TK & 90 & 89 \\
\hline
\end{tabular}




\begin{tabular}{|c|c|c|c|}
\hline MINK1 & STE & 90 & 100 \\
\hline MKK4 & STE & 81 & 87 \\
\hline MKK6 S207D/T211D** & STE & 70 & 96 \\
\hline MKK7 & STE & 83 & 78 \\
\hline MKNK1 & CAMK & 117 & 128 \\
\hline MKNK2 & CAMK & 98 & 63 \\
\hline MLK4 & TKL & 90 & 92 \\
\hline MST1 & STE & 86 & 105 \\
\hline MST2 & STE & 89 & 94 \\
\hline MST3 & STE & 28 & 14 \\
\hline MST4 & STE & 98 & 103 \\
\hline mTOR & ATYPICAL & 103 & 99 \\
\hline MUSK & TK & 80 & 113 \\
\hline MYLK & CAMK & 87 & 74 \\
\hline MYLK2 & CAMK & 113 & 112 \\
\hline MYLK3 & CAMK & 93 & 100 \\
\hline NEK1 & OTHER & 92 & 63 \\
\hline NEK11 & OTHER & 60 & 1 \\
\hline NEK2 & OTHER & 103 & 83 \\
\hline NEK3 & OTHER & 118 & 85 \\
\hline NEK4 & OTHER & 96 & 92 \\
\hline NEK6 & OTHER & 96 & 99 \\
\hline NEK7 & OTHER & 27 & 42 \\
\hline NEK9 & OTHER & 96 & 106 \\
\hline NIK & STE & 104 & 100 \\
\hline NLK & CMGC & 91 & 78 \\
\hline p38-alpha & CMGC & 96 & 111 \\
\hline p38-beta & CMGC & 101 & 104 \\
\hline p38-delta & CMGC & 91 & 85 \\
\hline p38-gamma & CMGC & 100 & 102 \\
\hline PAK1 & STE & 93 & 91 \\
\hline PAK2 & STE & 102 & 88 \\
\hline PAK3 & STE & 87 & 87 \\
\hline PAK4 & STE & 86 & 68 \\
\hline PAK6 & STE & 89 & 79 \\
\hline PAK7 & STE & 77 & 78 \\
\hline PASK & CAMK & 99 & 98 \\
\hline PBK & OTHER & 92 & 99 \\
\hline PCTAIRE1/CycY & CMGC & 87 & 53 \\
\hline PDGFR-alpha & TK & 97 & 103 \\
\hline PDGFR-beta & TK & 105 & 93 \\
\hline PDK1 & AGC & 82 & 94 \\
\hline PHKG1 & CAMK & 98 & 97 \\
\hline PHKG2 & CAMK & 92 & 88 \\
\hline PIM1 & CAMK & 108 & 109 \\
\hline PIM2 & CAMK & 81 & 77 \\
\hline PIM3 & CAMK & 105 & 100 \\
\hline PKA & AGC & 104 & 95 \\
\hline PKC-alpha & AGC & 107 & 100 \\
\hline
\end{tabular}




\begin{tabular}{|c|c|c|c|}
\hline PKC-beta1 & AGC & 94 & 99 \\
\hline PKC-beta2 & AGC & 75 & 84 \\
\hline PKC-delta & AGC & 100 & 119 \\
\hline PKC-epsilon & $\mathrm{AGC}$ & 133 & 132 \\
\hline PKC-eta & $\mathrm{AGC}$ & 78 & 90 \\
\hline PKC-gamma & AGC & 103 & 102 \\
\hline PKC-iota & AGC & 91 & 100 \\
\hline PKC-mu & $\mathrm{AGC}$ & 93 & 33 \\
\hline PKC-nu & AGC & 98 & 100 \\
\hline PKC-theta & $\mathrm{AGC}$ & 115 & 120 \\
\hline PKC-zeta & AGC & 107 & 109 \\
\hline PKMYT1 & OTHER & 84 & 88 \\
\hline PLK1 & OTHER & 101 & 99 \\
\hline PLK3 & OTHER & 91 & 91 \\
\hline PRK1 & AGC & 102 & 101 \\
\hline PRK2 & AGC & 91 & 78 \\
\hline PRKD2 & CAMK & 79 & 30 \\
\hline PRKG1 & $\mathrm{AGC}$ & 99 & 96 \\
\hline PRKG2 & $\mathrm{AGC}$ & 102 & 102 \\
\hline PRKX & $\mathrm{AGC}$ & 82 & 77 \\
\hline PYK2 & TK & 91 & 109 \\
\hline $\begin{array}{l}\text { RAF1 Y340D/Y341D } \\
\text { (untagged)** }\end{array}$ & TKL & 9 & 1 \\
\hline RET & TK & 69 & 81 \\
\hline RIPK2 & TKL & 70 & 5 \\
\hline RIPK5 & TKL & 83 & 82 \\
\hline ROCK1 & AGC & 98 & 104 \\
\hline ROCK2 & AGC & 100 & 103 \\
\hline RON & TK & 116 & 104 \\
\hline ROS & TK & 109 & 96 \\
\hline RPS6KA1 & AGC & 107 & 90 \\
\hline RPS6KA2 & AGC & 84 & 81 \\
\hline RPS6KA3 & AGC & 90 & 77 \\
\hline RPS6KA4 & AGC & 84 & 86 \\
\hline RPS6KA5 & AGC & 95 & 97 \\
\hline RPS6KA6 & AGC & 97 & 98 \\
\hline S6K & AGC & 87 & 75 \\
\hline S6K-beta & AGC & 90 & 98 \\
\hline SAK & OTHER & 44 & 6 \\
\hline SGK1 & AGC & 87 & 75 \\
\hline SGK2 & $\mathrm{AGC}$ & 91 & 101 \\
\hline SGK3 & AGC & 89 & 97 \\
\hline SIK1 & CAMK & 90 & 98 \\
\hline SIK2 & CAMK & 101 & 98 \\
\hline SIK3 & CAMK & 98 & 60 \\
\hline SLK & STE & 95 & 90 \\
\hline SNARK & CAMK & 81 & 90 \\
\hline SNK & OTHER & 91 & 94 \\
\hline SRC (GST-HIS-tag) & TK & 89 & 68 \\
\hline SRMS & TK & 70 & 10 \\
\hline
\end{tabular}




\begin{tabular}{|c|c|c|c|}
\hline SRPK1 & CMGC & 99 & 105 \\
\hline SRPK2 & CMGC & 108 & 111 \\
\hline STK17A & CAMK & 80 & 91 \\
\hline STK23 & CAMK & 97 & 105 \\
\hline STK25 & STE & 57 & 51 \\
\hline STK33 & CAMK & 82 & 76 \\
\hline STK39 & STE & 92 & 81 \\
\hline SYK aa1-635 & TK & 95 & 111 \\
\hline TAOK2 & STE & 84 & 35 \\
\hline TAOK3 & STE & 87 & 91 \\
\hline TBK1 & OTHER & 95 & 88 \\
\hline TEC & TK & 87 & 87 \\
\hline TGFB-R1 & TKL & 102 & 22 \\
\hline TGFB-R2 & TKL & 81 & 42 \\
\hline TIE2 & TK & 79 & 58 \\
\hline TLK1 & AGC & 92 & 108 \\
\hline TLK2 & AGC & 109 & 96 \\
\hline TNK1 & TK & 82 & 19 \\
\hline TRK-A & TK & 54 & 78 \\
\hline TRK-B & TK & 65 & 100 \\
\hline TRK-C & TK & 82 & 93 \\
\hline TSF1 & OTHER & 93 & 105 \\
\hline TSK2 & CAMK & 95 & 86 \\
\hline TSSK1 & CAMK & 88 & 84 \\
\hline TTBK1 & CK1 & 79 & 89 \\
\hline TTBK2 & CK1 & 104 & 104 \\
\hline TTK & OTHER & 90 & 92 \\
\hline TXK & TK & 71 & 88 \\
\hline TYK2 & TK & 92 & 96 \\
\hline TYRO3 & TK & 91 & 90 \\
\hline VEGF-R1 & TK & 111 & 84 \\
\hline VEGF-R2 & TK & 95 & 82 \\
\hline VEGF-R3 & TK & 76 & 94 \\
\hline VRK1 & CK1 & 82 & 77 \\
\hline VRK2 & CK1 & 116 & 103 \\
\hline WEE1 & OTHER & 87 & 91 \\
\hline WNK1 & OTHER & 103 & 98 \\
\hline WNK2 & OTHER & 101 & 103 \\
\hline WNK3 & OTHER & 91 & 89 \\
\hline YES & $\mathrm{TK}$ & 124 & 105 \\
\hline ZAK & TKL & 103 & 101 \\
\hline ZAP70 & TK & 95 & 92 \\
\hline \multicolumn{2}{|c|}{$\begin{array}{l}\text { Selectivity Score (portion of kinases with } \\
<50 \% \text { residual activity): }\end{array}$} & 0.030 & 0.093 \\
\hline
\end{tabular}

*Classification of protein kinase families (Manning et al. Science 6 December 2002: Vol. 298 no. 5600 pp. 1912-1934): AGC: containing PKA, PKG and PKC families

CAMK: Calcium/Calmoduline-dependent protein kinases

CK1: Casein kinase 1 -like

CMGC: containing CDK, MAPK, GSK3 and CLK families

TK: Tyrosine Kinase 
TKL: Tyrosine Kinase-like

STE: Homologs of Yeast Sterile 7, Sterile 11, Sterile 20 Kinases

** Constitutively active kinase 
Table S3. COMPARE Analyses of cellular response to dabrafenib_photo 2 (NSC:S789252) and to 100 synthetic compounds from the NCI database. The synthetic compounds are ranked in the order of similarity of cellular response to the response to $\mathbf{2}$. NSC $=$ numeric identifier for substances submitted to NCI for testing. NCI = National Cancer Institute, USA.

\begin{tabular}{|c|c|c|c|c|c|c|c|}
\hline Rank & Correlation & $\begin{array}{lr}\text { Seed } & \text { Vector } \\
\text { ident } & \text { For } \\
\text { Display } & \end{array}$ & $\begin{array}{lr}\text { Target } & \text { Vector } \\
\text { ident } & \text { For } \\
\text { Display } & \end{array}$ & $\begin{array}{ll}\text { Target } & \text { Vector } \\
\text { descriptor For Display }\end{array}$ & $\begin{array}{l}\text { Count } \\
\text { Commo } \\
\text { n Cell } \\
\text { Lines }\end{array}$ & $\begin{array}{l}\text { Seed } \\
\text { Standard } \\
\text { Deviatio } \\
\text { n }\end{array}$ & $\begin{array}{l}\text { Target } \\
\text { Standard } \\
\text { Deviatio } \\
\text { n }\end{array}$ \\
\hline 1 & 0.812 & NSC:S789252 & NSC:S755437 & & 58 & 29.893 & 0.673 \\
\hline 2 & 0.792 & NSC:S789252 & NSC:S755453 & & 56 & 29.992 & 0.518 \\
\hline 3 & 0.782 & NSC:S789252 & NSC:S764134 & $\begin{array}{l}\text { DABRAFENIB } \\
\text { MESYLATE }\end{array}$ & 52 & 29.923 & 1.361 \\
\hline 4 & 0.763 & NSC:S789252 & NSC:S761592 & & 57 & 28.115 & 0.627 \\
\hline 5 & 0.759 & NSC:S789252 & NSC:S761592 & & 59 & 29.885 & 0.66 \\
\hline 6 & 0.751 & NSC:S789252 & NSC:S755437 & & 59 & 29.885 & 0.662 \\
\hline 7 & 0.747 & NSC:S789252 & NSC:S761431 & ZELBORAF & 59 & 29.885 & 0.707 \\
\hline 8 & 0.731 & NSC:S789252 & NSC:S761586 & & 59 & 29.885 & 0.686 \\
\hline 9 & 0.731 & NSC:S789252 & NSC:S761584 & & 59 & 29.885 & 0.618 \\
\hline 10 & 0.723 & NSC:S789252 & NSC:S756457 & SB-610251-B & 59 & 29.885 & 0.33 \\
\hline 11 & 0.713 & NSC:S789252 & NSC:S755461 & & 56 & 29.992 & 0.521 \\
\hline 12 & 0.683 & NSC:S789252 & NSC:S766143 & & 56 & 30.357 & 0.439 \\
\hline 13 & 0.659 & NSC:S789252 & NSC:S756221 & GW405841X & 58 & 30.141 & 0.2 \\
\hline 14 & 0.655 & NSC:S789252 & NSC:S756456 & SB-590885-AAD & 59 & 29.885 & 0.813 \\
\hline 15 & 0.645 & NSC:S789252 & NSC:S756464 & SB-682330-A & 57 & 30.37 & 0.584 \\
\hline 16 & 0.631 & NSC:S789252 & NSC:S755435 & & 59 & 29.885 & 0.408 \\
\hline 17 & 0.629 & NSC:S789252 & NSC:S756376 & GW813360X & 59 & 29.885 & 0.2 \\
\hline 18 & 0.606 & NSC:S789252 & NSC:S633406 & & 58 & 30.115 & 0.234 \\
\hline 19 & 0.605 & NSC:S789252 & NSC:S757299 & $\begin{array}{l}\text { PROCHLORPERAZIN } \\
\text { E EDISYLATE (USAN) }\end{array}$ & 51 & 31.454 & 0.286 \\
\hline 20 & 0.598 & NSC:S789252 & NSC:S766538 & MMV666069 & 57 & 29.816 & 0.356 \\
\hline 21 & 0.586 & NSC:S789252 & NSC:S753193 & & 58 & 28.099 & 0.303 \\
\hline 22 & 0.583 & NSC:S789252 & NSC:S706829 & & 56 & 30.38 & 0.687 \\
\hline 23 & 0.58 & NSC:S789252 & NSC:S718507 & & 55 & 30.557 & 0.315 \\
\hline 24 & 0.578 & NSC:S789252 & NSC:S756458 & SB-614067-R & 59 & 29.885 & 0.354 \\
\hline 25 & 0.576 & NSC:S789252 & NSC:S707477 & & 51 & 30.005 & 0.249 \\
\hline 26 & 0.572 & NSC:S789252 & NSC:S683437 & & 53 & 30.338 & 0.273 \\
\hline 27 & 0.571 & NSC:S789252 & NSC:S654294 & & 41 & 31.282 & 0.232 \\
\hline 28 & 0.57 & NSC:S789252 & NSC:S707469 & & 52 & 31.027 & 0.24 \\
\hline 29 & 0.568 & NSC:S789252 & NSC:S13477 & & 59 & 29.885 & 0.311 \\
\hline 30 & 0.564 & NSC:S789252 & NSC:S46061 & & 57 & 29.923 & 0.278 \\
\hline 31 & 0.554 & NSC:S789252 & NSC:S656082 & & 45 & 31.046 & 0.464 \\
\hline 32 & 0.554 & NSC:S789252 & NSC:S721875 & & 56 & 30.146 & 0.251 \\
\hline 33 & 0.549 & NSC:S789252 & NSC:S760091 & $\begin{array}{l}\text { MEPARTRICIN } \\
\text { (USAN) }\end{array}$ & 56 & 30.425 & 0.213 \\
\hline 34 & 0.547 & NSC:S789252 & NSC:S667672 & & 55 & 30.127 & 0.306 \\
\hline
\end{tabular}




\begin{tabular}{|c|c|c|c|c|c|c|c|}
\hline 35 & 0.546 & NSC:S789252 & NSC:S644609 & & 43 & 32.302 & 0.265 \\
\hline 36 & 0.546 & NSC:S789252 & NSC:S683710 & & 51 & 30.605 & 0.228 \\
\hline 37 & 0.546 & NSC:S789252 & NSC:S701104 & & 57 & 29.523 & 0.503 \\
\hline 38 & 0.541 & NSC:S789252 & NSC:S354462 & HYPOTHEMYCIN & 58 & 30.115 & 0.699 \\
\hline 39 & 0.534 & NSC:S789252 & NSC:S722656 & $\begin{array}{ll}\text { PARTRICIN } & \text { A } \\
\text { MORPHOLIDE } & \end{array}$ & 55 & 30.724 & 0.138 \\
\hline 40 & 0.532 & NSC:S789252 & NSC:S71755 & $\begin{array}{l}\text { CARPHENAZINE } \\
\text { MALEATE(USAN) }\end{array}$ & 59 & 29.885 & 0.242 \\
\hline 41 & 0.531 & NSC:S789252 & NSC:S688369 & & 54 & 29.801 & 0.172 \\
\hline 42 & 0.529 & NSC:S789252 & NSC:S757349 & $\begin{array}{l}\text { THIORIDAZINE } \\
\text { HYDROCHLORIDE }\end{array}$ & 54 & 31.123 & 0.239 \\
\hline 43 & 0.527 & NSC:S789252 & NSC:S758434 & $\begin{array}{l}\text { HYCANTHONE } \\
\text { (USAN) }\end{array}$ & 59 & 29.885 & 0.159 \\
\hline 44 & 0.524 & NSC:S789252 & NSC:S756661 & $\begin{array}{l}\text { CHLORPROMAZINE } \\
\text { (USAN) }\end{array}$ & 58 & 29.856 & 0.266 \\
\hline 45 & 0.522 & NSC:S789252 & NSC:S119608 & & 58 & 30.114 & 0.348 \\
\hline 46 & 0.519 & NSC:S789252 & NSC:S78714 & $\begin{array}{l}\text { CLOTHIXAMIDE } \\
\text { MALEATE (USAN) }\end{array}$ & 59 & 29.885 & 0.31 \\
\hline 47 & 0.519 & NSC:S789252 & NSC:S355147 & & 54 & 28.016 & 0.087 \\
\hline 48 & 0.518 & NSC:S789252 & NSC:S665686 & & 58 & 30.115 & 0.257 \\
\hline 49 & 0.516 & NSC:S789252 & NSC:S756685 & CLEMASTINE (USAN) & 56 & 30.342 & 0.276 \\
\hline 50 & 0.513 & NSC:S789252 & NSC:S628119 & & 47 & 31.183 & 0.232 \\
\hline 50 & -0.4 & NSC:S789252 & NSC:S685262 & & 57 & 29.532 & 0.162 \\
\hline 48 & -0.403 & NSC:S789252 & NSC:S647044 & & 46 & 31.972 & 0.396 \\
\hline 49 & -0.403 & NSC:S789252 & NSC:S643125 & & 44 & 32.388 & 0.492 \\
\hline 46 & -0.404 & NSC:S789252 & NSC:S665313 & & 55 & 30.294 & 0.262 \\
\hline 47 & -0.404 & NSC:S789252 & NSC:S127445 & $\begin{array}{l}\text { ASPERGILLIC ACID, } \\
\text { HYDROXY }\end{array}$ & 50 & 28.137 & 0.34 \\
\hline 45 & -0.405 & NSC:S789252 & NSC:S641210 & & 49 & 31.493 & 0.492 \\
\hline 43 & -0.407 & NSC:S789252 & NSC:S728318 & & 57 & 30.358 & 0.887 \\
\hline 44 & -0.407 & NSC:S789252 & NSC:S634232 & & 43 & 32.393 & 0.235 \\
\hline 42 & -0.409 & NSC:S789252 & NSC:S668840 & & 50 & 32.06 & 0.188 \\
\hline 40 & -0.41 & NSC:S789252 & NSC:S631542 & & 48 & 31.81 & 0.313 \\
\hline 41 & $\begin{array}{c}-0.41 \\
\end{array}$ & NSC:S789252 & NSC:S646609 & & 46 & 31.873 & 0.375 \\
\hline 39 & -0.411 & NSC:S789252 & NSC:S647753 & $\begin{array}{l}\text { ANTINEOPLASTIC- } \\
\text { D647753 }\end{array}$ & 44 & 29.978 & 0.724 \\
\hline 37 & -0.412 & NSC:S789252 & NSC:S633925 & & 45 & 31.5 & 0.204 \\
\hline 38 & -0.412 & NSC:S789252 & NSC:S761834 & & 54 & 30.211 & 0.419 \\
\hline 36 & -0.413 & NSC:S789252 & NSC:S691569 & & 49 & 30.545 & 0.2 \\
\hline 34 & -0.415 & NSC:S789252 & NSC:S632990 & ABRIN A & 42 & 30.615 & 0.135 \\
\hline 35 & -0.415 & NSC:S789252 & NSC:S688323 & & 57 & 30.378 & 0.254 \\
\hline 33 & -0.416 & NSC:S789252 & NSC:S719179 & & 57 & 30.365 & 0.373 \\
\hline 31 & -0.419 & NSC:S789252 & NSC:S646606 & & 53 & 30.615 & 0.253 \\
\hline 32 & -0.419 & NSC:S789252 & NSC:S694493 & & 58 & 30.115 & 0.346 \\
\hline 29 & -0.424 & NSC:S789252 & NSC:S625735 & & 46 & 32.265 & 0.187 \\
\hline 30 & -0.424 & NSC:S789252 & NSC:S700429 & & 49 & 27.741 & 0.135 \\
\hline 27 & -0.428 & NSC:S789252 & NSC:S635453 & & 41 & 31.813 & 0.862 \\
\hline
\end{tabular}




\begin{tabular}{|c|c|c|c|c|c|c|c|}
\hline 28 & -0.428 & NSC:S789252 & NSC:S642397 & & 46 & 32.034 & 0.518 \\
\hline 26 & -0.429 & NSC:S789252 & NSC:S666607 & & 56 & 30.553 & 1.038 \\
\hline 25 & -0.43 & NSC:S789252 & NSC:S635536 & & 44 & 31.276 & 0.204 \\
\hline 24 & -0.432 & NSC:S789252 & NSC:S690741 & & 50 & 31.672 & 0.251 \\
\hline 23 & -0.434 & NSC:S789252 & NSC:S724628 & & 56 & 30.628 & 0.397 \\
\hline 22 & -0.437 & NSC:S789252 & NSC:S682690 & & 52 & 30.295 & 0.21 \\
\hline 21 & -0.438 & NSC:S789252 & NSC:S638643 & & 57 & 30.361 & 0.398 \\
\hline 20 & -0.442 & NSC:S789252 & NSC:S117181 & $\begin{array}{l}\text { CYCLOPIAZONIC } \\
\text { ACID }\end{array}$ & 42 & 33.4 & 0.35 \\
\hline 19 & -0.443 & NSC:S789252 & NSC:S651362 & & 45 & 31.026 & 0.187 \\
\hline 18 & -0.445 & NSC:S789252 & NSC:S654626 & & 41 & 32.356 & 0.32 \\
\hline 17 & -0.451 & NSC:S789252 & NSC:S642396 & & 46 & 32.034 & 0.542 \\
\hline 16 & -0.454 & NSC:S789252 & NSC:S635961 & & 44 & 32.426 & 0.356 \\
\hline 15 & -0.459 & NSC:S789252 & NSC:S642401 & & 46 & 32.034 & 0.509 \\
\hline 14 & -0.46 & NSC:S789252 & NSC:S345646 & OLEASIDE A & 55 & 28.717 & 0.235 \\
\hline 13 & -0.467 & NSC:S789252 & NSC:S642399 & & 46 & 32.034 & 0.5 \\
\hline 12 & -0.482 & NSC:S789252 & NSC:S646610 & & 43 & 31.655 & 0.363 \\
\hline 10 & -0.484 & NSC:S789252 & NSC:S743434 & & 58 & 30.115 & 0.418 \\
\hline 11 & -0.484 & NSC:S789252 & NSC:S646608 & & 46 & 31.873 & 0.353 \\
\hline 9 & -0.485 & NSC:S789252 & NSC:S642398 & & 46 & 32.034 & 0.513 \\
\hline 8 & -0.486 & NSC:S789252 & NSC:S646604 & & 52 & 29.598 & 0.341 \\
\hline 7 & -0.488 & NSC:S789252 & NSC:S653438 & & 58 & 30.115 & 0.511 \\
\hline 6 & -0.495 & NSC:S789252 & NSC:S642400 & & 46 & 32.034 & 0.497 \\
\hline 5 & -0.505 & NSC:S789252 & NSC:S627875 & & 46 & 32.452 & 0.154 \\
\hline 4 & -0.508 & NSC:S789252 & NSC:S645317 & $\begin{array}{l}\text { SANGUILUTINE } \\
\text { PSEUDOBASE }\end{array}$ & 42 & 30.531 & 0.435 \\
\hline 3 & -0.51 & NSC:S789252 & NSC:S721194 & & 52 & 27.878 & 0.164 \\
\hline 2 & -0.511 & NSC:S789252 & NSC:S642402 & & 44 & 32.654 & 0.52 \\
\hline 1 & -0.521 & NSC:S789252 & NSC:S658361 & & 41 & 30.264 & 0.426 \\
\hline
\end{tabular}




\section{Methods}

\subsection{Photochemical Characterization}

\subsubsection{UV/Vis Absorption Spectra}

Spectra were recorded on UV/Vis spectrophotometer Varian Cary ${ }^{\circledR} 50$ Scan (Agilent Technologies, CA, USA). UV/Vis absorbance was measured in TE buffer (10 mM Tris, $1 \mathrm{mM}$ EDTA, $\mathrm{pH} 7.5)$. Concentration of compounds was $0.02 \mathrm{mM}$. For the DNA titration experiments $0.04 \mathrm{mM}$ of 2 were mixed $1+1$ with $0.36,0.18$ and 0.09 mM calf thymus DNA. The solutions were incubated for two minutes at room temperature. The end concentration of 2 was $0.02 \mathrm{mM}$.

\subsubsection{Fluorescence Emission Spectra}

Spectra were recorded on LS55 Fluorescence spectrometer (Perkin Elmer, Waltham, MA, USA). The excitation and emission slits were set to $10 \mathrm{~nm}$. The fluorescence was measured in TE buffer (10 mM Tris, $1 \mathrm{mM} \mathrm{EDTA,} \mathrm{pH} \mathrm{7.5).}$ Concentration of compounds was $0.04 \mathrm{mM}$. The emission spectrum of dabrafenib (1) was recorded at constant excitation with $330 \mathrm{~nm}$. Dabrafenib_photo (2) was excited at $370 \mathrm{~nm}$. For the DNA titration experiments $0.04 \mathrm{mM}$ of 2 were mixed $1+1$ with $0.36,0.18$ and $0.09 \mathrm{mM}$ calf thymus DNA. The solutions were incubated for two minutes at room temperature and then excited at $375 \mathrm{~nm}$. The end concentration of 2 was $0.02 \mathrm{mM}$.

\subsubsection{Dabrafenib stability under daylight exposure and in the dark}

Compound 1 was dissolved in DMSO $(1.1 \mathrm{mM})$. The solution was placed in a clear glass flask on a windowsill. After particular incubation times samples were taken, diluted 1:2 with methanol and analyzed by HPLC. Additional to HPLC analysis LC-MS was used to confirm compound identity. The same experiment was repeated in DMEM (200 $\mu$ M solution of 1). Moreover, $200 \mu \mathrm{M}$ solutions of $\mathbf{1}$ in DMEM and in DMSO were also incubated at $37{ }^{\circ} \mathrm{C}$ in the dark. The samples were measured as described above.

\subsubsection{Irradiation of dabrafenib solutions at $365 \mathrm{~nm}$.}

Compound 1 was dissolved in DMSO, DPBS and DMEM $(200 \mu \mathrm{M})$ and the solutions were irradiated at $365 \mathrm{~nm}$ (LED source: 16x Nichia. NCSU276A.U365, Sahlmann Photochemical Solutions, Figure S8) with $1130 \mathrm{~W} / \mathrm{m}^{2}$ and $226 \mathrm{~W} / \mathrm{m}^{2}$ for up to $15 \mathrm{~min}$. After determined irradiation times samples were taken. Aliquots were diluted 1:2 with methanol and subsequently analyzed by HPLC. Additional to retention time LC-MS was used to proof the identity.

\subsection{Molecular modeling}

Molecular modeling was performed on a DELL 4 core system. For visualization Maestro, version 9.7, Schrödinger, LLC, (New York, NY, USA, 2014) was used. Protein crystal structures were prepared prior to docking by the Protein Preparation Wizard (1) utilizing the following programs: Epik, version 2.7, 2014 (2); Prime, version 2.4, 2014 (3). Thus, the X-ray crystal structure refinement process included addition of hydrogen atoms, optimization of hydrogen bonds, and removal of atomic clashes. Default settings were used. Missing side chains and loops were filled in with Prime. Furthermore, selenomethionines were converted to methionines and water molecules were deleted.

Additionally, ligands were prepared in order to create energetically minimized 3D geometries and assign proper bond orders (MacroModel, version 10.3, 2014 (4)). Accessible tautomer and ionization states were calculated prior to screening (LigPrep, version 2.9, 2014 (5)). To generate bioactive conformers a conformational search method was used (ConfGen, version 2.7, 2014 (6)). Receptor grid generation was performed by Glide, version 6.2, 2014 (7). For ligand docking the Glide SP workflow was used. Energetically minimized ligand conformations were docked into the active site of the protein; possible binding poses were determined and subsequently ranked based on their calculated binding affinities. 


\subsection{Kinase Assays}

\subsubsection{Determination of $\mathrm{IC}_{50}$ values}

The $\mathrm{BRAF}^{\mathrm{V} 600 \mathrm{E}} \mathrm{IC}_{50}$ profile for $\mathbf{1}$ and $\mathbf{2}$ was determined using $\mathrm{BRAF}^{\mathrm{V} 600 \mathrm{E}}$ protein kinase by a radiometric ${ }^{33}$ PanQinase ${ }^{\circledR}$ assay (8). $\mathrm{IC}_{50}$ values were measured by testing 10 semi-log concentrations of each compound in the range from $1 \times 10^{-5} \mathrm{M}$ to $3 \times 10^{-10} \mathrm{M}$, for single samples. Prior to testing, the compounds were dissolved to prepare $1 \times 10^{-3} \mathrm{M}$ stock solutions in $100 \%$ DMSO. The final DMSO concentration in the reaction cocktails was $1 \%$ in all cases. Analyses were performed by ProQinase (Freiburg, Germany).

\subsubsection{Kinase profiling}

Compounds 1 and 2 were screened against 321 kinases. The used method was radiometric protein kinase assay $\left({ }^{33}\right.$ PanQinase ${ }^{\circledR}$ Activity Assay) (8). The substances were dissolved in DMSO at a concentration of $100 \mu \mathrm{M}$. The final DMSO concentration in all reaction cocktails (including high and low controls) was $1 \%$ The mean percentage residual kinase activity was determined. Analyses were performed by ProQinase (Freiburg, Germany).

\subsection{Cellular Assays}

\subsubsection{Cell culture}

SKMEL28 cells were purchased from CLS Cell Lines Service GmbH (Eppelheim, Germany). The cells were grown in DMEM medium with $2 \mathrm{mM}$ L-Glutamine, $1 \mathrm{mM}$ Sodium Pyruvate and 10\%. SKMEL28 cells were incubated in a 5\% $\mathrm{CO}_{2}$ humidified atmosphere at $37^{\circ} \mathrm{C}$.

\subsubsection{Proliferation Assays}

The cells were grown in cell flasks until approximately $90 \%$ confluence and then seeded to give 21000 cells in $100 \mu 1$ per well into 96-well CulturePlates ${ }^{\mathrm{TM}}$ (Perkin Elmer). In addition to the test plates, one plate was prepared for reference measurement at day zero. All plates were incubated for $24 \mathrm{~h}$ at $37{ }^{\circ} \mathrm{C}$ in a humidified atmosphere with $5 \% \mathrm{CO}_{2}$. Compounds 1, and 2 were dissolved in 100\% DMSO (v/v) and added to the test plates. The final DMSO concentration in the assay was $0.5 \%(\mathrm{v} / \mathrm{v})$. Viability of the cells in the day zero control plates were determined on the same day without adding any compounds. For viability measurement the resazurin assay was used. The shift in the fluorescence signal was measured at the LS55 Fluorescence spectrometer (Perkin Elmer). For the photoactivation experiments the test plates were irradiated at $365 \mathrm{~nm}$ for $5 \mathrm{~min}$ (LED source: 16x Nichia NCSU276a, Sahlmann Photochemical Solutions, 5\%, $1.13 \mathrm{~kW} / \mathrm{m}^{2}$ ). Test plates were incubated for further $48 \mathrm{~h}$ and cell viability was defined as described above. Measured raw data was converted into percent of cell growth by using the high control (0.5\% DMSO (v/v) without compound) and the day zero control. For dose-response studies, 11 different concentrations of compounds were tested in duplicates. $\mathrm{IC}_{50}$ values were calculated using the 4-parameter logarithmic fit option of GraphPad Prism 5.

\subsubsection{Cell Staining}

SKMEL28 cells were stained with the dabrafenib (1) and 2. For this purpose, the cells were seeded to give 15,000 cells in $50 \mu \mathrm{L}$ per well into 96-well half area microplate (Ref.: 675986, Greiner bio-one, Kremsmünster, Austria). The plate was incubated for $72 \mathrm{~h}$ at $37{ }^{\circ} \mathrm{C}$ in a humidified atmosphere with $5 \% \mathrm{CO}_{2}$. Compounds 1 and 2 were dissolved in DMEM medium with $10 \%$ FCS and added to the cells to give the end concentration of $100 \mu \mathrm{M}$, respectively. The cells were incubated with the compounds for $15 \mathrm{~min}$ at $37^{\circ} \mathrm{C}$. Where indicated the cells were irradiated at $365 \mathrm{~nm}$ with $1.13 \mathrm{~kW} / \mathrm{m}^{2}$. After that, the cells were washed twice with DPBS and fixed with 3.3\% formalin for $20 \mathrm{~min}$. Then the cells were washed twice with DPBS again and the cell nuclei were counterstained with $1 \mu \mathrm{g} / \mathrm{mL}$ DAPI in PBS. After 10 min incubation at $37^{\circ} \mathrm{C}$, the cells were washed with DPBS and the fluorescence images were taken at the ImageXpress ${ }^{\circledR}$ Micro XL 
(Molecular Devices, Sunnyvale CA, USA). The magnification was 60x and 10x. Following filter sets were used for the visualization of compounds (Table S4).

Table S4. Filter sets used for the cell staining.

$\begin{array}{llll}\text { Compound } & \text { Filter Set } & \text { Exciter }(\mathbf{n m})(\text { Center/Bandwidth) } & \text { Emitter }(\mathbf{n m})(\text { Center/Bandwidth }) \\ \text { DAPI } & \text { DAPI } & 377 / 50 & 447 / 60 \\ & & & \\ \mathbf{1 , 2} & \text { CFP } & 438 / 24 & 483 / 32\end{array}$

\subsection{Agarose gel electrophoresis}

The $1 \%$ agarose gel was prepared by dissolving $0.5 \mathrm{~g}$ agarose in $50 \mathrm{ml}$ of boiling TAE (Tris base, acetic acid and EDTA) buffer. $1 \mu \mathrm{l}$ of $10 \mu \mathrm{g} / \mu \mathrm{l}$ ethidium bromide was added to the hot solution.

$4 \mu \mathrm{l}$ of a PCR product (DNA, $800 \mathrm{bp}, 100 \mathrm{ng} / \mu \mathrm{l}$ ) were mixed with $1 \mu \mathrm{l}$ of $\mathbf{1}$ and $\mathbf{2}$ in different concentrations. For two positive controls the same amount of nucleotide was incubated with $1 \mu \mathrm{l}$ of ethidium bromide or DAPI (100 ng/ $\mu 1$, respectively). After $10 \mathrm{~min}$ of incubation at room temperature $1 \mu \mathrm{l}$ of loading buffer (TAE buffer with glycerol and Orange $\mathrm{G}$ ) was added. The samples were then loaded on $1 \%$ agarose gel. The gel electrophoresis was run for $30 \mathrm{~min}$ at $120 \mathrm{~V}$. The visualization was performed at the Lumi-Imager F1 Workstation (Roche Life Sciences, Mannheim, Germany). The individual lines and bands were analyzed by LumiAnalyst 3.1 Image Analysis Software.

\subsection{Chemistry}

All reagents and solvents were obtained from commercial sources and used as received. Reagents were purchased from abcr GmbH (Karlsruhe, Germany), Fisher Scientific GmbH/Acros (Schwerte, Germany), Sigma-Aldrich Chemie (Hamburg, Germany) or VWR International GmbH (Hannover, Germany).

Where appropriate, column chromatography was performed for crude precursors with Merck (Darmstadt, Germany) silica gel $60(0.063-0.200 \mathrm{~mm})$ or Acros Organics silica gel $(0.060-0.200 \mathrm{~mm}$; pore diameter ca. $60 \mathrm{~nm})$. Column chromatography was performed on a LaFlash system (VWR) using silica gel columns (PF-30SIHP, $30 \mu \mathrm{m}, 40 \mathrm{~g}$, puriFlash) or RP18 columns (PF-15C18HP, $15 \mu \mathrm{m}, 55 \mathrm{~g}$, puriFlash). The crude product was loaded on Merck silica gel 60 (15$40 \mu \mathrm{m}$ ). The progress of reactions was monitored by thin-layer chromatography (TLC) utilizing silica gel polyester sheets (SIL G/UV254, 0.2 mm, Polygram ${ }^{\circledR}$, Macherey-Nagel GmbH, Düren, Germany.

High-performance liquid chromatography (HPLC) analyses were performed on a 1050 Series system (Hewlett Packard, Ratingen , Germany). As column an Agilent ZORBAX ${ }^{\circledR}$ Eclipse XDB-C8, $5 \mu \mathrm{m}(4.6 \mathrm{~mm} \times 150 \mathrm{~mm})$ was used. Injection volume of the compound solutions was $20 \mu \mathrm{L}$. As mobile phase (flow rate $1.5 \mathrm{~mL} / \mathrm{min}$ ) served a gradient of $\mathrm{KH}_{2} \mathrm{PO}_{4}$ buffer (10 mM, pH 2.3) and methanol over $14 \mathrm{~min}$. The detection wavelength was adapted to the according UV/vis absorption spectra. All key compounds submitted to biological assays were proven by this method to show $\geq 98 \%$ purity.

Melting points were determined on a SMP3 apparatus (Stuart Scientific, Staffordshire, UK) and are uncorrected. ${ }^{1} \mathrm{H}-$ (300 MHz) and ${ }^{13} \mathrm{C}-(75 \mathrm{MHz})$ NMR were recorded on an Avance III 300 spectrometer (Bruker, Rheinstetten, Germany) at $300 \mathrm{~K}$ with a multinuclear probe head using the manufacturer's pulse programs. The data are reported as follows: chemical shifts in ppm from $\mathrm{Me}_{4} \mathrm{Si}$ (TMS) as external standard, multiplicity and coupling constant (Hz). NMR spectra were obtained on a ${ }^{1} \mathrm{H}(300 \mathrm{MHz})$ and ${ }^{13} \mathrm{C}$ spectra $(75 \mathrm{MHz})$ were referenced either to TMS or to internal DMSO-d $5\left({ }^{1} \mathrm{H}-\mathrm{NMR} \delta 2.50\right)$ and internal DMSO- $\mathrm{d}_{6}\left({ }^{13} \mathrm{C}-\mathrm{NMR} \delta 39.5\right)$ or internal $\mathrm{CHCl}_{3}\left({ }^{1} \mathrm{H}-\mathrm{NMR} \delta 7.26\right)$ and internal $\mathrm{CDCl}_{3}\left({ }^{13} \mathrm{C}-\mathrm{NMR} \delta 77.0\right)$. All 
coupling constants ( $\mathrm{J}$ values) are quoted in Hz. The following NMR abbreviations are used: b (broad), s (singlet), d (doublet), $\mathrm{t}$ (triplet), $\mathrm{m}$ (unresolved multiplet). The labeling scheme of structures to correlate NMR signals is included in the data.

LC-MS samples were chromatographically separated utilizing a 1100 HPLC system (Agilent, Waldbronn, Germany) consisting of a thermostated autosampler, diode array detection, and an Agilent ZORBAX ${ }^{\circledR}$ Eclipse XDB-C8, $5 \mu \mathrm{m}$ $(4.6 \mathrm{~mm} \times 150 \mathrm{~mm})$. Elution was achieved with a solvent gradient system of water and acetonitrile, with $0.1 \%$ of acetic acid and a flow rate of $1 \mathrm{~mL} / \mathrm{min}$. The eluent flow was splitted to the mass spectrometer. Mass spectrometry was carried out using a Bruker Esquire LC instrument (Bruker Daltonik, Bremen, Germany), with electrospray ionization (ESI) operating in the positive ion mode. Following parameters were used: drying gas nitrogen $8 \mathrm{~L} / \mathrm{min}$, nebulizer 35 psi, dry gas heating $350{ }^{\circ} \mathrm{C}$, HV capillary $4000 \mathrm{~V}$, HV EndPlate offset $-500 \mathrm{~V}$

\section{Chemical synthesis and Compound Characterization}

\section{$N$-(5-amino-2-tert-butyl)-11-fluorbenzol[f]thiazol-[4,5- $h$ ]-quinazolin-10-yl)-2,6-difluorbenzolsulfonamide}

\section{= Dabrafenib_photo $(2)$}

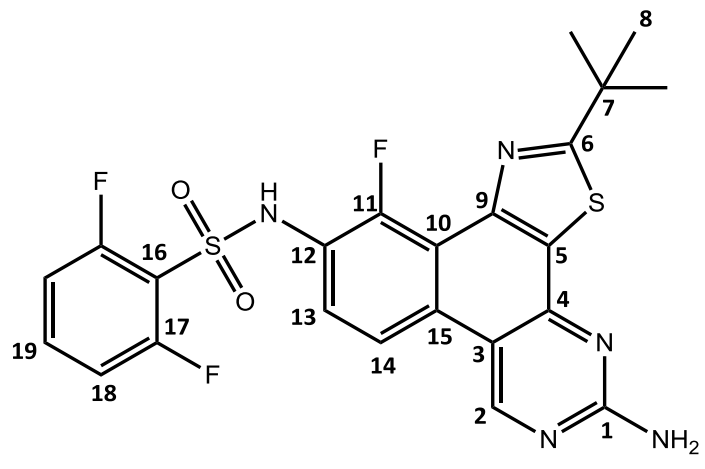

$\mathrm{C}_{23} \mathrm{H}_{18} \mathrm{~F}_{3} \mathrm{~N}_{5} \mathrm{O}_{2} \mathrm{~S}_{2}(\mathrm{Mr}=517.09)$

Solution of $5 \mathrm{mg}(9.6 \mu \mathrm{mol})$ dabrafenib in $2 \mathrm{ml}$ THF was irradiated at $365 \mathrm{~nm}$ with $5.4 \mathrm{~W}$ for 2 min. This procedure was repeated 18 times at room temperature. The reaction batches were combined. The total initial weight of dabrafenib was $101 \mathrm{mg}(190 \mu \mathrm{mol})$. The solvent was removed under reduced pressure and the residue was purified by the flash chromatography $\left(\mathrm{SiO}_{2}\right.$ reversed phase, $\mathrm{MeOH} /$ water gradient 50:50 to 100:0) to give compound 2 as a yellowish solid (36.2 mg, $70.0 \mu \mathrm{mol}$, yield: $37 \%$ ).

${ }^{1} \mathrm{H}-\mathrm{NMR}$ (DMSO-d $\left.6,300 \mathrm{MHz}\right): \delta=1.52(\mathrm{~s}, 9 \mathrm{H}, \mathrm{H}-8), 7.28\left(\mathrm{~m}, 2 \mathrm{H}, \mathrm{NH} \mathrm{H}_{2}\right), 7.28\left(\mathrm{ddd},{ }^{5} \mathrm{~J}=0.4 \mathrm{~Hz},{ }^{4} \mathrm{~J}=1.7 \mathrm{~Hz},{ }^{3} J=8.5\right.$ $\left.\mathrm{Hz},{ }^{3} J=8.9 \mathrm{~Hz}, 2 \mathrm{H}, H-18\right), 7.59\left(\mathrm{dd},{ }^{3} \mathrm{~J}=7.4 \mathrm{~Hz},{ }^{3} J=7.8 \mathrm{~Hz}, 1 \mathrm{H}, H-13\right), 7.71\left(\mathrm{tt},{ }^{4} \mathrm{~J}=6.1 \mathrm{~Hz},{ }^{3} \mathrm{~J}=8.5 \mathrm{~Hz}, 1 \mathrm{H}, H-19\right)$, $8.56\left(\mathrm{dd},{ }^{4} \mathrm{~J}=0.9 \mathrm{~Hz},{ }^{3} \mathrm{~J}=9.3 \mathrm{~Hz}, 1 \mathrm{H}, H-14\right), 9.79$ (s, $\left.1 \mathrm{H}, H-2\right), 11.01$ (s, $\left.1 \mathrm{H}, \mathrm{NH}\right) \mathrm{ppm}$.

${ }^{13} \mathrm{C}-\mathrm{NMR}\left(\mathrm{DMSO}-\mathrm{d}_{6}, 300 \mathrm{MHz}\right): \delta=30.4(\mathrm{~s}, C-8), 38.3(\mathrm{~s}, C-7), 110.9\left(\mathrm{~d},{ }^{4} J_{C F}=1.6 \mathrm{~Hz}, C-3\right), 113.4\left(\mathrm{dd},{ }^{2} J_{C F}=22.7 \mathrm{~Hz}\right.$, $\left.{ }^{2} J_{C H}=3.5 \mathrm{~Hz}, C-18\right), 114.6\left(\mathrm{~d},{ }^{3} J_{C F}=10.3 \mathrm{~Hz}, C-9\right), 117.4\left(\mathrm{~d},{ }^{2} J_{C F}=16.1 \mathrm{~Hz}, C-16\right), 117.6\left(\mathrm{dd},{ }^{4} J_{C F}=0.54 \mathrm{~Hz},{ }^{2} J_{C H}=4.4\right.$ $\mathrm{Hz}, C-13), 120.8\left(\mathrm{~d},{ }^{2} J_{C F}=12.3 \mathrm{~Hz}, C-10\right), 125.4(\mathrm{~s}, C-13), 129.3\left(\mathrm{~d},{ }^{3} J_{C F}=3.9 \mathrm{~Hz}, C-15\right), 130.6(\mathrm{~s}, C-5), 135.9\left(\mathrm{tt},{ }^{3} J_{C F}=\right.$ $\left.10.9 \mathrm{~Hz},{ }^{2} J_{C H}=3.3 \mathrm{~Hz}, C-19\right), 148.8\left(\mathrm{dd},{ }^{2} J_{C F}=0.54 \mathrm{~Hz},{ }^{2} J_{C H}=7.2 \mathrm{~Hz}, C-12\right), 149.2(\mathrm{~s}, C-4), 150.1$ (s, $\left.C-11\right), 157.1160 .5$ $\left(\mathrm{dd},{ }^{3} J_{F F}=257.3 \mathrm{~Hz},{ }^{2} J_{C F}=3.61 \mathrm{~Hz}, C-4\right), 157.9(\mathrm{~s}, C-2), 162.1(\mathrm{~s}, C-1), 184.0(\mathrm{~s}, C-6) \mathrm{ppm}$.

\footnotetext{
${ }^{15} \mathrm{~N}-\mathrm{HMBC}\left(\mathrm{DMSO}-\mathrm{d}_{6}, 300 \mathrm{MHz}\right): \delta=9.79 /-119.60,11.01 /-268.37 \mathrm{ppm}$.

${ }^{19}$ F-NMR (DMSO-d 6 , $\left.300 \mathrm{MHz}\right): \delta=-121.03$ (s, 1 F, F-11), -107.18 (m, 2 F, F-17) ppm.
}

HRMS (EI, $\left.205^{\circ} \mathrm{C}, \mathrm{THF}\right): \mathrm{m} / \mathrm{z}=517.0849[\mathrm{M}]^{+}$.

LC-MS (ESI, $70 \mathrm{eV}, \mathrm{MeOH}): \mathrm{t}_{\mathrm{R}}=9.3 \mathrm{~min} ; \mathrm{m} / \mathrm{z}(\%)=518.1(100)[\mathrm{M}+\mathrm{H}]^{+}$. 
IR (ATR): $\tilde{v}=3490(\mathrm{~N}-\mathrm{H}), 3176(\operatorname{arom} . \mathrm{C}-\mathrm{H}), 2926\left(\mathrm{C}-\mathrm{H}_{3}\right), 1696(\mathrm{~N}=\mathrm{N}), 1613(\mathrm{~N}-\mathrm{H}), 1587,1522,1488,1469$ (arom. $\mathrm{C}=\mathrm{C}$ ), 1342 (sulfonamide), 1277, 1240, $1174(\mathrm{C}-\mathrm{F}) \mathrm{cm}^{-1}$. 


\section{Supplementary References}

1. Schrödinger Release 2014-2: Schrödinger Suite 2014-2 Protein Preparation Wizard; Epik version 2.8, Schrödinger, LLC, New York, NY, 2014; Impact version 6.3, Schrödinger, LLC, New York, NY, 2014; Prime version 3.6, Schrödinger, LLC, New York, NY, 2014.

2. Schrödinger Release 2014-1: Epik, version 2.7, Schrödinger, LLC, New York, NY, 2014.

3. Small-Molecule Drug Discovery Suite 2014-2: PrimeX, version 2.4, Schrödinger, LLC, New York, NY, 2014.

4. Schrödinger Release 2014-1: MacroModel, version 10.3, Schrödinger, LLC, New York, NY, 2014.

5. Schrödinger Release 2014-1: LigPrep, version 2.9, Schrödinger, LLC, New York, NY, 2014.

6. Schrödinger Release 2014-1: ConfGen, version 2.7, Schrödinger, LLC, New York, NY, 2014.

7. Small-Molecule Drug Discovery Suite 2014-1: Glide, version 6.2, Schrödinger, LLC, New York, NY, 2014.

8. ProQinase GmbH. FlashPlate-basedProtein Kinase Assay Protocol (33 PanQinase® Assay) (accessed February 17, 2016).

9. Hastie, C. J.; McLauchlan, H. J.; Cohen, P. Assay of protein kinases using radiolabeled ATP: a protocol. Nature protocols 2006, 1 (2), 968-971. DOI: 10.1038/nprot.2006.149.

10. Bain, J.; Plater, L.; Elliott, M.; Shpiro, N.; Hastie, C. J.; McLauchlan, H.; Klevernic, I.; Arthur, J. S. C.; Alessi, D. R.; Cohen, P. The selectivity of protein kinase inhibitors: a further update. The Biochemical journal 2007, 408 (3), $297-$ 315. DOI: 10.1042/BJ20070797. 